\title{
Modeling, Design \& Simulation of an Adaptive Neuro- Fuzzy Inference System (ANFIS) for Speed Control of Induction Motor
}

\author{
Ashok Kusagur \\ Research Scholar, EEE Dept., \\ JNTU, Hyderabad-85, Andhra \\ Pradesh, India, \\ Professor \& Head of the \\ Department, HMSIT, Tumkur-4, \\ Karnataka, India.
}

\author{
Dr. S. F. Kodad \\ Director, \\ Krishnamurthy Inst. of Tech. \& \\ Engg., Hyderabad, Andhra Pradesh, \\ India.
}

\author{
Dr. B V. Sankar Ram \\ Professor, Dept. of EEE, \\ JNTUCE, Kukatpally, Hydarabad- \\ 85, Andhra Pradesh, India.
}

\begin{abstract}
A novel design of an adaptive neuro fuzzy inference strategy (ANFIS) for controlling some of the parameters, such as speed, torque, flux, voltage, current, etc. of the induction motor is presented in this paper. Induction motors are characterized by highly non-linear, complex and time-varying dynamics and inaccessibility of some of the states and outputs for measurements. Hence it can be considered as a challenging engineering problem in the industrial sector. Various advanced control techniques has been devised by various researchers across the world. Some of them are based on the fuzzy techniques. Fuzzy logic based controllers are considered as potential candidates for such an application. Fuzzy based controllers develop a control signal which yields on the firing of the rule base, which is written on the previous experiences \& these rules are fired which is random in nature. As a result of which, the outcome of the controller is also random \& optimal results may not be obtained. Selection of the proper rule base depending upon the situation can be achieved by the use of an ANFIS controller, which becomes an integrated method of approach for the control purposes \& yields excellent results, which is the highlight of this paper. In the designed ANFIS scheme, neural network techniques are used to select a proper rule base, which is achieved using the back propagation algorithm. This integrated approach improves the system performance, cost-effectiveness, efficiency, dynamism, reliability of the designed controller. The simulation results presented in this paper show the effectiveness of the method developed \& has got faster response time or settling times. Further, the method developed has got a wide number of advantages in the industrial sector $\&$ can be converted into a real time application using some interfacing cards.
\end{abstract}

\section{General Terms}

Controller design, Damping, Oscillations.

\section{Keywords}

ANFIS, Fuzzy Logic, Membership functions, ANN, Controller, Simulink, Matlab, Induction motor, Closed loop, Parameter.

\section{INTRODUCTION}

Intelligent, self-learning or self-organizing controls using expert systems, artificial intelligence, fuzzy logic, neural networks, hybrid networks, etc have been recently recognized as the important tools to improve the performance of the power electronics based drive systems in the industrial sectors. Combination of this intelligent control with the adaptiveness appears today as the most promising research area in the practical implementation \& control of electrical drives. The design and implementation of industrial control systems often relies on quantitative mathematical models of the plants (say, induction motors, generators, DC motors, etc), the controllers, etc. At times, however, we encounter problems for which controller design becomes very difficult and expensive to obtain. In such cases, it is often necessary to observe human experts or experienced operators of the plants or processes and discover rules governing their actions for automatic control [33]. In this context, the fuzzy logic concepts coupled with artificial neural networks play a very important role in developing the controllers for the plant.

Induction motors play a vital role in the industrial sector especially in the field of electric drives \& control. Without proper controlling of the speed, it is virtually impossible to achieve the desired task for a specific application. AC motors, particularly the squirrel-cage induction motors (SCIM), enjoy several inherent advantages like simplicity, reliability, low cost and virtually maintenance-free electrical drives. However, for high dynamic performance industrial applications, their control remains a challenging problem because they exhibit significant nonlinearities and many of the parameters, mainly the rotor resistance, vary with the operating conditions [42]. Field orientation control (FOC) or vector control [53] of an induction machine achieves decoupled torque and flux dynamics leading to independent control of the torque and flux as for a separately excited DC motor. FOC methods are attractive, but suffer from one major disadvantage, viz., they are sensitive to motor parametric variations such as the rotor time constant and an incorrect flux measurement or estimation at low speeds [52].

Consequently, performance deteriorates and a conventional controller such as a PID is unable to maintain satisfactory performance under these conditions. Recently, there has been observed an increasing interest in combining artificial intelligent control tools with classical control techniques [42]. The principal motivations for such a hybrid implementation is that with fuzzy logic, neural networks \& rough sets issues, such as uncertainty or unknown variations in plant parameters and structure can be dealt with more effectively, hence improving the robustness of the control system. Conventional controls have on their side wellestablished theoretical backgrounds on stability and allow 
different design objectives such as steady state and transient characteristics of the closed loop system to be specified. Several works were contributed to the design of such hybrid control schemes which was shown by various researchers in [12], [48]. Classical control systems like PI, PID control have been used, together with vector control methods, for the speed control of induction machines by various researchers [6]. The main drawbacks of the linear control approaches were the sensitivity in performance to the system parameters variations and inadequate rejection of external perturbations and load changes [8].

Induction motors are widely used in various industries as prime work-horses to produce rotational motions and forces. Generally, variable-speed drives for induction motors require both wide operating range of speed and fast torque response, regardless of load variations. Usually, the classical control is used in majority of the electrical motor drives. Conventional control makes use of the mathematical model for the controlling of the system. When there are system parametric variations or environmental disturbance (say noise), behavior of system is not satisfactory $\&$ deviates from the desired performance [11].

In addition, usual computation of system mathematical model is difficult or impossible. To obtain the exact mathematic model of the system, then one has to do some identification techniques such as the system identification \& obtain the plant model. Moreover, the design and tuning of conventional controller increases the implementation cost and adds additional complexity in the control system \& thus, may reduce the reliability of the control system. Hence, the fuzzy based techniques are used to overcome this kind of problems. Efficient torque control of induction motor drives in combination with resonant DC-link input filters can lead to a type of stability problem that is known as negative impedance instability. To overcome this, Henrik et.al., proposed a solution to the above problem by using the concept of non-linear system stabilizing controller in [29] with the plant.

Recent years have witnessed rapidly growing popularity of fuzzy control systems in engineering applications. The numerous successful applications of fuzzy control have sparked a flurry of activities in the analysis and design of fuzzy control systems [34]. Fuzzy logic based flexible multi-bus voltage control of power systems was developed by Ashok et.al. in [32]. In the last few years, fuzzy logic has met a growing interest in many motor control applications due to its non-linearities handling features and independence of the plant modeling. The fuzzy controller (FLC) operates in a knowledge-based way, and its knowledge relies on a set of linguistic if-then rules, like a human operator.

Ashok et.al. [5] developed a novel design of a Takagi-Sugeno fuzzy strategy for induction motor speed control, which yielded excellent results, especially in the settling times of the various responses. Ramon et.al. [46] presented a rule-based fuzzy logic controller applied to a scalar closed loop induction motor control with slip regulation \& they also compared their results with those of a PI controller. They used a new linguistic rule table in FLC to adjust the motor control speed. A fuzzy controller of the type of the Takagi-Sugeno model was investigated in [15] by Chen \& Wong. AI based design of a fuzzy logic scheme for speed control of induction motors using SVPWM technique was proposed by the authors Ashok et.al. in [3].

There are a number of significant control methods available for induction motors including scalar control, vector or field-oriented control, direct torque and flux control, sliding mode control, and the adaptive control [11]. Scalar control is aimed at controlling the induction machine to operate at the steady state, by varying the amplitude and frequency of the fundamental supply voltage [13]. A method to use of an improved V/f control for high voltage induction motors \& its stability was proposed in [9]. The scalar controlled drive, in contrast to vector or field-oriented controlled one, is easy to implement, but provides somewhat inferior performance. This control method provides limited speed accuracy especially in the low speed range and poor dynamic torque response.

T-S fuzzy model-based impulsive control of chaotic systems with exponential decay rate was discussed by X. Liu, and S. Zhong in [37]. In their paper, they presented a new approach for stability analysis of the fuzzy impulsive controllers in which the fuzzy system was presented by Takagi-Sugeno model. Further, Ashok et.al. [5] used the TS model to develop a hybrid control scheme to control the speed of the IM, which yielded excellent results. Zhang \& Jiang proposed an efficient approach for indirect fieldoriented control of induction machines based on the synergetic control method, taking speed control of an induction motor by using an example in [56].

Space Vector Pulse Width Modulation (SVPWM) method is one of the advanced, computation-intensive PWM method and possibly the best among all the PWM techniques for variable frequency drive applications. Because of its superior performance characteristics, it has been finding widespread applications in recent years. Satean, et.al., presented a novel control technique of control of the induction motors using space vector pulse width modulation method in [47]. They even developed an excellent 3$\phi$ bridge inverter which was used to apply a balanced $3 \phi$ voltages to the SCIM. In due course, fuzzy logic concept was introduced by Lotfi Zadeh in 1965. Many researchers used this FLC concept developed by Zadeh to develop controllers for their applications, which had yielded good results. Thus, this FLC concept remained as a popular control scheme in the control world even today. Arulmozhiyal \& Baskaran [45] described in brief a number of fuzzy control logic applications on various plants in their paper. They even devised a new control strategy to control the speed of IMs using FLC technique.

Fuzzy Logic control (FLC) has proven effective for complex, nonlinear and imprecisely defined processes for which standard model based control techniques are impractical or impossible [19]. Fuzzy Logic, deals with problems that have vagueness, uncertainty and use membership functions with values varying between 0 and 1 [18]. This means that if the reliable data is not available or if the controlled system is too complex to derive the required decision rules, development of a fuzzy logic controller become quite difficult. In this case, the expert knowledge can be made use of for framing the proper rules which can be further used to tune the controller for obtaining better results [57]. Furthermore, an optimal fuzzy logic controller cannot be achieved by trial-and-error. These drawbacks have limited the application of fuzzy logic control [28].

Some efforts have been made to solve these problems and simplify the task of tuning parameters and developing rules for the controller [40]. These approaches mainly use adaptation or learning techniques drawn from artificial intelligence or neural network theories. Application of fuzzy logic control for the 
control a speed induction motor using space vector pulse width modulation is not quite new [44]. However, there is no systematic method for designing and tuning the fuzzy logic controller \& one has to design using some trail \& error using the IF, ELSE, THEN rules. Neuro fuzzy robust controllers for AC drive systems using predictive controller was developed by Yashuhiko et.al. [55] which reduced the plant $\&$ the observation noise.

Consoli et.al. presented an adaptive vector based control of IM drives based on neuro fuzzy approach in their paper in [20]. They performed an experimental realization of an MRAC speed controller for the indirect field oriented IM drives based on fuzzy laws for the adaptive process \& a neuro-fuzzy procedure to optimize the fuzzy rules. A model reference adaptive flux observer based adaptive neuro-fuzzy control (ANFIS) of IM drives was presented by Nasir Uddin \& Hao Wen in [43]. The observer model was developed based on a reference flux model \& a closed loop gopinath flux observer, which combines current \& voltage model flux observes. They investigated the performance of the designed drive at different dynamic operating conditions. A simple DTC neuro-fuzzy control of PWM inverter fed IM drive was proposed by Grabowski, Marian \& Bose in [25]. They applied an adaptive neuro fuzzy inference system to achieve highperformance decoupled flux \& torque control using an experimental approach coupled with DSP TMS320C31 card. Aware et.al. [7] proposed a new type of adaptive neuro-fuzzy controller (ANFIS) for voltage source inverted fed IMs. In this paper, they replaced the conventional PI / PID controller by the fuzzy controller in speed controller loop \& implemented using DSP interfacing card. ANFIS which tunes the fuzzy inference system with a back propagation algorithm based on a collection of input-output data is implemented here.

Mihoub et.al. [39] proposed a ANFIS controller to obtain a high dynamic performance in AC machines. In their work, they used fuzzy controller first \& then the neuro-fuzzy controller. Finally, they proved that the latter one is better than the former one in terms of the dynamism. An excellent sensorless speed control of IM drives using a robust $\&$ adaptive neuro fuzzy based intelligent controller was formulated by Farzan Rashidi [23]. An ANN was adopted to estimate the motor speed \& to provide a sensorless speed estimator system by evaluating for a wide range of operating conditions such as start ups, step changes in the reference speeds, unknown load torque with parameter variations. An IM spindle motor drive using synchronous PWM \& dead time compensatory techniques with an ANFIS controller was proposed by Faa \& Rong for advanced spindle motor applications by performing an real time experiment [22]. Since the control characteristics \& motor parameters for the high speed IM drive were time varying, they proposed an ANFIS scheme to control the rotor speed. The plant here was identified by a fuzzy NN identifier to provide the sensitivity info of the drive system to the adaptive controller using a back propagation algo to train the network online. Mokhtar \& Sofiane [41] developed an adaptive speed control of an hybrid fuzzy-neural network for a high performance IM drive to improve the performance \& robustness of the IM drive under non-linear loads \& parametric variations.

Many researchers had worked on the fuzzy logic based on-line efficiency control for an indirect vector controlled IM drive. Bimal Bose et.al. [10] extended the same control technique to a stator flux oriented electric vehicle IM drive \& then implemented the fuzzy controller by a dynamic back propagation algorithm using an ANFIS controller. They further verified the simulated results using an DSP based hardware. Haider et.al. [27] presented the design and implementation of Fuzzy-SMC-PI methodology to control the flux and speed of an induction motor. The Fuzzy-SMC-PI was basically a combination of Sliding Mode Control (SMC) and PI control methodologies through fuzzy logic, but the drawback being the chattering during the time of switching.

In [16] \& [36], the researchers implemented a fuzzy logic controller to adjust the boundary layer width according to the speed error. The drawback of their controller is that it depends on the equivalent control \& on the system parameters. Two researchers, Takagi \& Sugeno developed a excellent control scheme for control of various applications in the industrial sector. This controller had many advantages over the other methods discussed so far. Many researchers started using their models for their applications. Zie, Ling \& Jhang [54] presented a TS model identification method by which a great number of systems whose parameters vary dramatically with working states can be identified via Fuzzy Neural Networks (FNN). The suggested method could overcome the drawbacks of traditional linear system identification methods which are only effective under certain narrow working states and provide global dynamic description based on which further control of such systems may be carried out.

In the above mentioned papers, there were a lot of drawbacks \& disadvantages, one of the parameter being the settling time of the responses \& the proper selection of the rule base. The responses had taken a lot of time to reach the final steady state value. In this paper, a sincere attempt is made to reduce the settling time of the responses $\&$ make the speed of response very fast by designing an efficient controller using ANFIS control strategy. The proper rule base is selected using an intelligently developed back propagation algo. Here, we have formulated this complex control strategy for the speed control of IM, which has yielded excellent results compared to the others mentioned in the literature survey above. The results of our work have showed a very low transient response and a non-oscillating steady state response with excellent stabilization.

The structure of the research work (flow / organization of the paper) presented in this paper is organized in the following sequence. A brief review of the literature survey of the related work was presented in the previous paragraphs in the introductory section. Section 2 presents the mathematical modelling of the induction motor. Review about the adaptive neuro fuzzy inference scheme used in the design of the controller is presented in section 3. The design of the ANFIS controller is presented in section 4 . The section 5 shows the development of the simulink model for the speed control of the induction motor. The simulation results $\&$ the discussion on it are presented in the section 6 . This is followed by the conclusions in the concluding section, the nomenclatures, abbreviations, references $\&$ the author biographies.

\section{MODELLING OF INDUCTION MOTOR}

In the control of any power electronics drive system (say a motor); to start with, a mathematical model of the plant is required. This mathematical model is required further to design any type of controller to control the process of the plant. The mathematical model can be obtained by various methods, viz., from first 
principles, system identification methods, etc. This mathematical model may be a linear / non-linear differential equation or a transfer function (in $s$ or $z$-domain) or in state space form. In this section, we present the mathematical model of the induction motor. The mathematical model of the SCIM system used in our work consists of space vector PWM voltage source inverter, induction motor, direct flux and the torque control [56].

The drawback of the coupling effect in the control of SCIMs is that, it gives sluggish response and the system is easily prone to instability because of a high-order system effect. This problem can be solved by making use of either vector control or field-oriented control. When this type of control strategy is adopted, it can make an induction motor to be controlled like a separately excited DC motor. Of course, the control of AC drives can exhibit better performance. Thus, due to the above mentioned reasons, an induction motor model was established using a rotating $(d, q)$ field reference (without saturation) concept [56]. The power circuit of the 3- $\phi$ induction motor is shown in the Fig. 1.

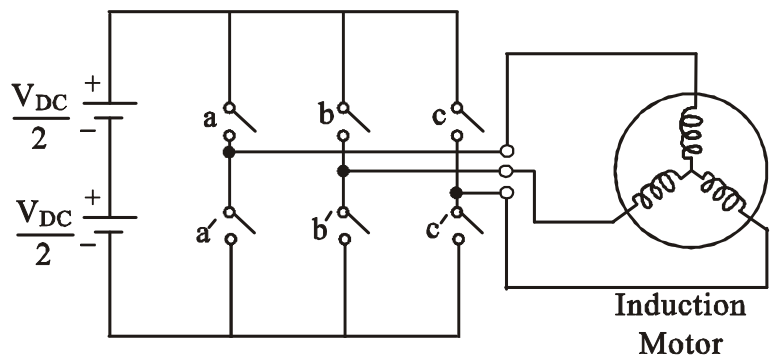

Fig. 1 : Power circuit connection diagram for the IM

The equivalent circuit used for obtaining the mathematical model of the induction motor is shown in the Fig. 2.

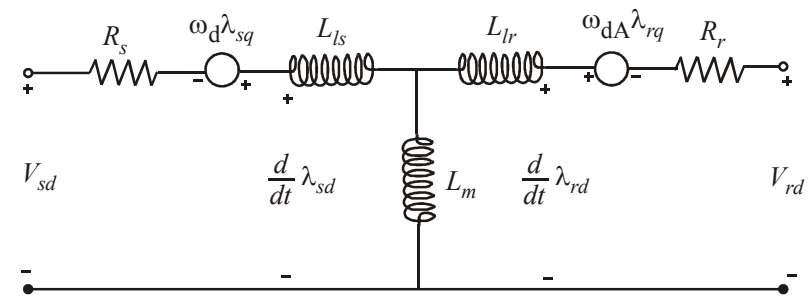

(a) $d$-axis

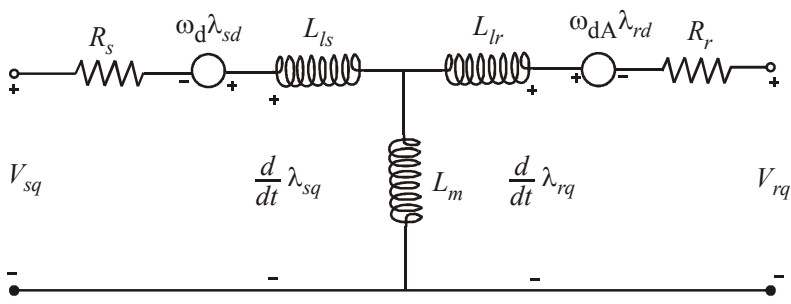

(b) $q$-axis

Fig. 2 : Equivalent circuit of induction motor in $d$ - $q$ frame

An induction motor model is then used to predict the voltage required to drive the flux, torque $\&$ the speed to the demanded values. This calculated voltage is then synthesized using the space vector modulation. The stator $\&$ rotor voltage equations are given by [56]

$$
\begin{aligned}
& V_{s d}=R_{s} i_{s d}+\frac{d}{d t} \lambda_{s d}-\omega_{d} \lambda_{s q}, \\
& V_{s q}=R_{s} i_{s q}+\frac{d}{d t} \lambda_{s q}+\omega_{d} \lambda_{s d}, \\
& V_{r d}=R_{r} i_{r d}+\frac{d}{d t} \lambda_{r d}-\omega_{d A} \lambda_{r q} \\
& V_{r q}=R_{r} i_{r q}+\frac{d}{d t} \lambda_{r q}+\omega_{d A} \lambda_{r d},
\end{aligned}
$$

where $V_{s d}$ and $V_{s q}, V_{r d}$ and $V_{r q}$ are the direct axes \& quadrature axes stator and rotor voltages [56].

The squirrel-cage induction motor considered for the simulation study in this paper, has the $d$ and $q$-axis components of the rotor voltage zero. The flux linkages to the currents are related by the Eq. (5) as

$$
\left[\begin{array}{c}
\lambda_{s d} \\
\lambda_{s q} \\
\lambda_{r d} \\
\lambda_{r q}
\end{array}\right]=M\left[\begin{array}{l}
i_{s d} \\
i_{s q} \\
i_{r d} \\
i_{r q}
\end{array}\right] ; M=\left[\begin{array}{cccc}
L_{s} & 0 & L_{m} & 0 \\
0 & L_{s} & 0 & L_{m} \\
L_{m} & 0 & L_{r} & 0 \\
0 & L_{m} & 0 & L_{r}
\end{array}\right] .
$$

The electrical part of an induction motor can thus be described by a fourth-order state space model which is given in Eq. (6), by combining equations (1) - (5) as [56]

$$
\left[\begin{array}{c}
v_{q s} \\
v_{d s} \\
v_{q r} \\
v_{q r}
\end{array}\right]=\left[\begin{array}{cccc}
R_{s}+s L_{s} & -\omega_{e} L_{s} & s L_{m} & -\omega_{b} L_{m} \\
-\omega_{e} L_{s} & R_{s}+s L_{s} & -\omega_{e} L_{m} & p L_{m} \\
s L_{m} & \left(\omega_{e}-\omega_{r}\right) L_{m} & R_{r}+s L_{r} & \left(\omega_{e}-\omega_{r}\right) L_{r} \\
-\left(\omega_{e}-\omega_{r}\right) L_{m} & s L_{m} & -\left(\omega_{e}-\omega_{r}\right) L_{r} & R_{r}+s L_{r}
\end{array}\right]\left[\begin{array}{c}
i_{q s} \\
i_{d s} \\
i_{q r} \\
i_{q r}
\end{array}\right],
$$

where $s$ is the laplacian operator. By superposition, i.e., adding the torques acting on the $d$-axis and the $q$-axis of the rotor windings, the instantaneous torque produced in the electromechanical interaction is given by

$$
T_{e m}=\frac{3}{2}\left(\frac{P}{2}\right)\left(\lambda_{r q} i_{r d}-\lambda_{r d} i_{r q}\right) \text {. }
$$

The electromagnetic torque expressed in terms of inductances is given by

$$
T_{e m}=\frac{3}{2}\left(\frac{P}{2}\right) L_{m}\left(i_{s q} i_{r d}-i_{s d} i_{r q}\right) \text {. }
$$

The mechanical part of the motor is modeled by the equation [56].

$\frac{d}{d t} \omega_{M e c h}=\frac{T_{e m}-T_{L}}{J_{e q}}=\frac{\frac{3}{2}\left(\frac{P}{2}\right) L_{m}\left(i_{s q} i_{r d}-i_{s d} i_{r q}\right)-T_{L}}{J_{e q}}$,

where,

$J_{e q}=$ Equivalent Moment of Inertia,

$\omega_{d A}=\omega_{\text {slip }}=\omega_{s}-\omega_{m}$,

$L_{s}=L_{s l}+L_{m}, L_{r}=L_{r l}+L_{m}$.

This IMs mathematical model is further used to design a adaptive controller using ANFIS control strategy in the next but next section. The induction motor can be observed as a system of electric and magnetic circuits, which are coupled magnetically and electrically. A 3-Phase balanced sinusoidal voltages given by [56]. 
$V_{A n}=V_{m} \cos \omega t$

$V_{B n}=V_{m} \cos \left(\omega t-\frac{2 \pi}{3}\right)$,

$V_{C n}=V_{m} \cos \left(\omega t+\frac{2 \pi}{3}\right)$

are applied to the IM using the equation

$\mathbf{V}=\frac{2}{3}\left[v_{A n}+a v_{B n}+a^{2} v_{C n}\right]$

through the 3-Phase bridge inverter shown in the Fig. 1 which has got 8 permissible switching states. This 8 permissible switching states can be graphically represented as shown in the Fig. 3. The table I gives the summary of the switching states and the corresponding phase-to-neutral voltages of the isolated neutral induction machine [47].

\begin{tabular}{|l|l|l|l|l|l|l|}
\hline $\mathbf{V}_{i}$ & $a$ & $b$ & $c$ & $V_{A n}$ & $V_{B n}$ & $V_{C n}$ \\
\hline$V_{0}$ & 0 & 0 & 0 & 0 & 0 & 0 \\
\hline$V_{1}$ & 1 & 0 & 0 & $2 V_{D C} / 3$ & $-V_{D C} / 3$ & $-V_{D C} / 3$ \\
\hline$V_{2}$ & 1 & 1 & 0 & $V_{D C} / 3$ & $V_{D C} / 3$ & $-2 V_{D C} / 3$ \\
\hline$V_{3}$ & 0 & 1 & 0 & $-V_{D C} / 3$ & $2 V_{D C} / 3$ & $-V_{D C} / 3$ \\
\hline$V_{4}$ & 0 & 1 & 1 & $-2 V_{D C} / 3$ & $V_{D C} / 3$ & $V_{D C} / 3$ \\
\hline$V_{5}$ & 0 & 0 & 1 & $-V_{D C} / 3$ & $-V_{D C} / 3$ & $2 V_{D C} / 3$ \\
\hline$V_{6}$ & 1 & 0 & 1 & $V_{D C} / 3$ & $-2 V_{D C} / 3$ & $V_{D C} / 3$ \\
\hline$V_{7}$ & 1 & 1 & 1 & 0 & 0 & 0 \\
\hline
\end{tabular}

Table I: The inverter switching states

\section{Review of Adaptive Neuro Fuzzy Inference Scheme}

In this section, a brief review of the ANFIS concepts to control various system parameters of the plant is presented. The concept of neural networks started in the late-1800s as an effort to describe how the human mind performed in the olden days. As years rolled by, these neural networks started playing a very important role in the various engineering applications. Neural networks have been applied successfully to speech recognition, image analysis and adaptive control, in order to construct software agents or autonomous robots \& in the control of machines. ANNs are a family of intelligent algorithms which can be used for time series prediction, classification, and control and identification purposes. Neural networks have an ability to train with various parameter of induction motor. As a non-linear function, they can be used for identifying the extremely nonlinear system parameters with high accuracy. Recently, the use of neural networks, to identify and control nonlinear dynamic systems has been proposed because they can approximate a wide range of non-linear functions to any desired degree of accuracy. Moreover, they have the advantages of extremely fast parallel computation and fault tolerance characteristics. Also there have been some investigations into the application of NNs to power electronics and ac drives, including speed estimation. This technique gives a fairly good estimate of the speed and is robust to parameter variation. However, the neural network speed estimator should be trained sufficiently with various patterns to get good performance [23].

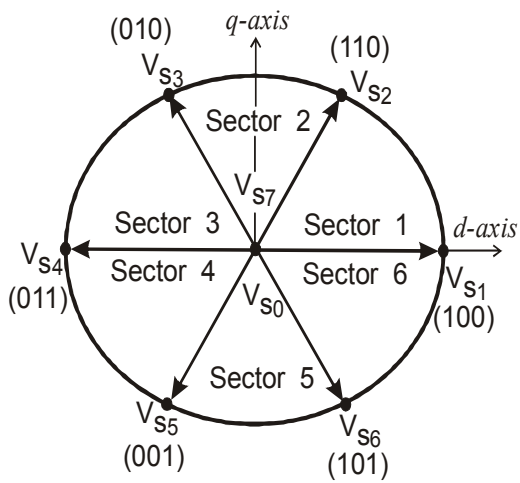

Fig. 3 : Diagrammatic representation of the sequence of the space vectors

Fuzzy logic is one of the successful applications in the control engineering field which can be used to control various parameters of the real time systems. This logic combined with neural networks yields very significant results. Neural networks can learn from data. However, understanding the knowledge learned by neural networks has been difficult. To be more specific, it is usually difficult to develop an insight about the meaning associated with each neuron and each weight. In contrast, fuzzy rule based models are easy to be understood because it uses linguistic terms and the structure of IF-THEN rules. Unlike neural networks, however, fuzzy logic by itself can not learn. The learning and identification of fuzzy logic systems need to adopt techniques from other areas, such as statistics, system identification. Since neural networks can learn, it is natural to merge these two techniques. This merged technique of the learning power of the NNs with the knowledge representation of FL has created a new hybrid technique, called as the term 'neuro fuzzy networks' [23].

Since ANFIS design starts with a pre-structured system, DOF for learning is limited, i.e., the MF of input \& output variables contain more information that $\mathrm{NN}$ has to drive from sampled data sets. Knowledge regarding the systems under design can be used right from the start. Part of the system can be excluded from the training. Hence, this ANFIS process is more efficient. The rules are in the linguistic forms and so intermediate results can be analyzed and interpreted easily. The modification of rules is possible during the training and optimization can be done manually. Further the ANFIS strategy supports the TS based systems. To start the ANFIS learning; first, a training data set that contains the desired input / output data pairs of target systems to be modeled is to be required. The design parameters required for any ANFIS controller are viz., Number of data pairs, Training data set \& checking data sets, Fuzzy inference systems for training, Number of epochs to be chosen to start the training, Learning results to be verified after mentioning the step size [7]. 
In this context, the general ANFIS control structure for the control of any plant is presented here as follows [25], [43]. This structure contains the same components as the FIS, expect for the NN block. The structure of the network is composed of a set of units (and connections) arranged into five connected network layers, viz., $l_{1}$ to $l_{5}$ as shown in the Fig. 18 .

Layer 1: This layer consists of input variables (membership functions), viz., input $1 \&$ input 2 . Here, triangular or bell shaped MF can be used. This layer just supplies the input values $x_{i}$ to the next layer, where $i$ $=1$ to $n$.

Layer 2: This layer (membership layer) checks for the weights of each MFs. It receives the input values $x_{i}$ from the $1^{\text {st }}$ layer and act as MFs to represent the fuzzy sets of the respective input variables. Further, it computes the membership values which specify the degree to which the input value $x_{i}$ belongs to the fuzzy set, which acts as the inputs to the next layer.

Layer 3: This layer is called as the rule layer. Each node (each neuron) in this layer performs the pre-condition matching of the fuzzy rules, i.e., they compute the activation level of each rule, the number of layers being equal to the number of fuzzy rules. Each node of these layers calculates the weights which are normalized.

Layer 4: This layer is called as the defuzzification layer \& provides the output values $y$ resulting from the inference of rules. Connections between the layers $l_{3}$ $\& l_{4}$ are weighted by the fuzzy singletons that represent another set of parameters for the neuro fuzzy network.

Layer 5: This layer is called as the output layer which sums up all the inputs coming from the layer 4 and transforms the fuzzy classification results into a crisp (binary).

The ANFIS structure is tuned automatically by least-squareestimation \& the back propagation algorithm. The algorithm shown above is used in the next section to develop the ANFIS controller to control the various parameters of the induction motor. Because of its flexibility, the ANFIS strategy can be used for a wide range of control applications.

\section{Controller design}

A controller is a device which controls each \& every operation in the system making decisions. From the control system point of view, it is bringing stability to the system when there is a disturbance, thus safeguarding the equipment from further damages. It may be hardware based controller or a software based controller or a combination of both. In this section, the development of the control strategy for control of various parameters of the induction machine such as the speed, flux, torque, and voltage, current is presented using the concepts of ANFIS control scheme, the block diagram of which is shown in the Fig. 4.

To start with, we design the controller using the ANFIS scheme. Fuzzy logic is one of the successful applications of fuzzy set in which the variables are linguistic rather than the numeric variables. Linguistic variables, defined as variables whose values are sentences in a natural language (such as large or small), may be represented by the fuzzy sets. Fuzzy set is an extension of a 'crisp' set where an element can only belong to a set (full membership) or not belong at all (no membership). Fuzzy sets allow partial membership, which means that an element may partially belong to more than one set.

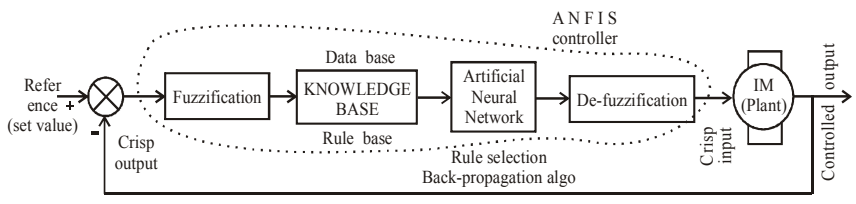

Fig. 4 : Block diagram of the ANFIS control scheme for the speed control of the IM

A fuzzy set A of a universe of discourse $\mathrm{X}$ is represented by a collection of ordered pairs of generic element and its membership function $\mu: X \rightarrow\left[\begin{array}{ll}0 & 1\end{array}\right]$, which associates a number $\mu \mathrm{A}(\mathrm{x}): \mathrm{X} \rightarrow\left[\begin{array}{ll}0 & 1\end{array}\right]$, to each element $\mathrm{x}$ of $\mathrm{X}$. A fuzzy logic controller is based on a set of control rules called as the fuzzy rules among the linguistic variables. These rules are expressed in the form of conditional statements.

Our basic structure of the developed ANFIS coordination controller to control the speed of the IM consists of 4 important parts, viz., fuzzification, knowledge base, neural network and the de-fuzzification blocks, which are explained in brief in further paragraphs.

The inputs to the ANFIS controller, i.e., the error $\&$ the change in error is modeled using the Eq. (20) as

$$
\begin{gathered}
e(k)=\omega_{r e f}-\omega_{r}, \\
\Delta e(k)=e(k)-e(k-1),
\end{gathered}
$$

where $\omega_{r e f}$ is the reference speed, $\omega_{r}$ is the actual rotor speed, is the $e(k)$ error and $\Delta e(k)$ is the change in error. The fuzzification unit converts the crisp data into linguistic variables, which is given as inputs to the rule based block. The set of 49 rules are written on the basis of previous knowledge / experiences in the rule based block.

The rule base block is connected to the neural network block. Back propagation algorithm is used to train the neural network to select the proper set of rule base. For developing the control signal, the training is a very important step in the selection of the proper rule base. Once the proper rules are selected \& fired, the control signal required to obtain the optimal outputs is generated.

The output of the NN unit is given as input to the de-fuzzification unit and the linguistic variables are converted back into the numeric form of data in the crisp form.

In the fuzzification process, i.e., in the first stage, the crisp variables, the speed error \& the change in error are converted into fuzzy variables or the linguistics variables. The fuzzification maps the 2 input variables to linguistic labels of the fuzzy sets. The fuzzy coordinated controller uses the linguistic labels. Each fuzzy label has an associated membership function. The membership function of triangular type is used in our work \& is shown in the Fig. 8. The inputs are fuzzified using the fuzzy sets $\&$ are given as input to ANFIS controller. The rule base for 
selection of proper rules using the back propagation algorithm is written as shown in the table II.

\begin{tabular}{|l|l|l|l|l|l|l|l|}
\hline $\begin{array}{l}\text { E } \\
\Delta \mathrm{N}^{2}\end{array}$ & $\mathrm{NB}$ & $\mathrm{NM}$ & $\mathrm{NS}$ & ZE & PS & PM & PB \\
\hline NB & NB & NB & NB & NB & NM & NS & ZE \\
\hline NM & NB & NB & NM & NM & NS & ZE & PS \\
\hline NS & NB & NM & NS & NS & ZE & PS & PM \\
\hline ZE & NB & NM & NS & ZE & PS & PM & PB \\
\hline PS & NM & NS & ZE & PS & PS & PM & PB \\
\hline PM & NS & ZE & PS & PM & PM & PB & PB \\
\hline PB & ZE & PS & PM & PB & PB & PB & PB \\
\hline
\end{tabular}

Table II : Rule base for controlling the speed.

The developed fuzzy rules $(7 \times 7)=49$ included in the ANFIS controller is given below in the form of an algorithm as follows :

1. If (speederror is NB) and (changeinerror is NB) then (output1 is NS) (1)

2. If (speederror is NB) and (changeinerror is NM) then (output1 is NS) (1)

3. If (speederror is NB) and (changeinerror is NS) then (output1 is NS) (1)

4. If (speederror is NB) and (changeinerror is NS) then (output1 is NS) (1)

5. If (speederror is NB) and (changeinerror is PS) then (output1 is NM) (1)

6. If (speederror is NB) and (changeinerror is PM) then (output1 is NS) (1)

7. If (speederror is NB) and (changeinerror is $\mathrm{PB}$ ) then (output1 is $\mathrm{Z}$ ) (1)

8. If (speederror is NM) and (changeinerror is NB) then (output1 is NS) (1)

9. If (speederror is NM) and (changeinerror is NM) then (output1 is NS) (1)

10.If (speederror is NM) and (changeinerror is NS) then (output1 is NB) (1)

11.If (speederror is NM) and (changeinerror is Z) then (output1 is NM) (1)

12.If (speederror is NM) and (changeinerror is PS) then (output1 is NS) (1)

13.If (speederror is NM) and (changeinerror is PM) then (output1 is Z) (1)

14.If (speederror is NM) and (changeinerror is PB) then (output1 is PS) (1)

15.If (speederror is NS) and (changeinerror is NB) then (output1 is NS) (1)

16.If (speederror is NS) and (changeinerror is NM) then (output1 is NB) (1)

17.If (speederror is NS) and (changeinerror is NS) then (output1 is NM) (1)

18.If (speederror is NS) and (changeinerror is Z) then (output1 is NS) (1)

19.If (speederror is NS) and (changeinerror is PS) then (output1 is Z) (1)

20.If (speederror is NS) and (changeinerror is PM) then (output1 is PS) (1)

21.If (speederror is NS) and (changeinerror is $\mathrm{PB}$ ) then (output1 is PM) (1)

22.If (speederror is $Z$ ) and (changeinerror is NB) then (output1 is NB) (1)

23.If (speederror is Z) and (changeinerror is NM) then (output1 is NM) (1)

24.If (speederror is Z) and (changeinerror is NS) then (output1 is NS) (1)

25.If (speederror is $\mathrm{Z}$ ) and (changeinerror is $\mathrm{PB}$ ) then (output1 is $\mathrm{PB}$ ) (1)

26.If (speederror is $Z$ ) and (changeinerror is $Z$ ) then (output1 is $Z$ ) (1)

27.If (speederror is $Z$ ) and (changeinerror is PS) then (output1 is PS) (1)

28.If (speederror is $Z$ ) and (changeinerror is PM) then (output1 is PM) (1)

29.If (speederror is PS) and (changeinerror is NB) then (output1 is NM) (1)

30.If (speederror is PS) and (changeinerror is NM) then (output1 is NS) (1)

31.If (speederror is PS) and (changeinerror is NS) then (output1 is Z) (1)

32.If (speederror is PS) and (changeinerror is Z) then (output1 is PS) (1)

33.If (speederror is PS) and (changeinerror is PS) then (output1 is PM) (1)

34.If (speederror is PS) and (changeinerror is PM) then (output1 is PB) (1)

35.If (speederror is PS) and (changeinerror is PB) then (output1 is PS) (1)

36.If (speederror is PM) and (changeinerror is NB) then (output1 is NS) (1)

37.If (speederror is PM) and (changeinerror is NM) then (output1 is Z) (1)

38.If (speederror is PM) and (changeinerror is NS) then (output1 is PS) (1)

39.If (speederror is PM) and (changeinerror is Z) then (output1 is PM) (1)

40.If (speederror is PM) and (changeinerror is PS) then (output1 is PB) (1)

41.If (speederror is PM) and (changeinerror is PM) then (output1 is PS) (1)

42.If (speederror is PM) and (changeinerror is PB) then (output1 is PB) (1)

43.If (speederror is $\mathrm{PB}$ ) and (changeinerror is NB) then (output1 is $\mathrm{Z}$ ) (1)

44.If (speederror is $\mathrm{PB}$ ) and (changeinerror is NM) then (output1 is PS) (1)

45.If (speederror is PB) and (changeinerror is NS) then (output1 is PM) (1)

46.If (speederror is $\mathrm{PB}$ ) and (changeinerror is $\mathrm{Z}$ ) then (output1 is PB) (1)

47.If (speederror is PB) and (changeinerror is PS) then (output1 is PB) (1)

48.If (speederror is PB) and (changeinerror is PM) then (output1 is PB) (1)

49.If (speederror is $\mathrm{PB}$ ) and (changeinerror is $\mathrm{PB}$ ) then (output1 is $\mathrm{PB}$ ) (1)

The control decisions are made based on the fuzzified variables in the Table II. The inference involves a set of rules for determining the output decisions. As there are 2 input variables \& 7 fuzzified variables, the controller has a set of 49 rules for the ANFIS controller. Out of these 49 rules [Fig. 9], the proper rules are selected by the training of the neural network with the help of back propagation algorithm \& these selected rules are fired. Further, it has to be converted into numerical output, i.e., they have to be de-fuzzified. This process is what is called as defuzzification, which is the process of producing a quantifiable result in fuzzy logic.

The defuzzifcation transforms fuzzy set information into numeric data information. There are so many methods to perform the defuzzifcation, viz., centre of gravity method, centre of singleton method, maximum methods, the marginal properties of the centroid methods \& so on. In our work, we use the centre of gravity method. The output of the defuzzification unit will generate the control commands which in turn is given as input (called as the crisp input) to the plant through the inverter. If there is any deviation in the controlled output (crisp output), this is fed back \& compared with the set value \& the error signal is generated which is given as input to the ANFIS controller which in turn brings back the output to the normal value, thus maintaining stability in the system. Finally, the controlled output signal, i.e., $y$ is given by Eq. (21) as

$$
y=\left(\sum_{i=1}^{R} \mu^{i} a_{1}^{i} x_{1}+\Lambda+\sum_{i=1}^{R} \mu^{i} a_{q}^{i} x_{q}\right) / \sum_{i=1}^{R} \mu^{i} .
$$

This controlled output $y$ is nothing but the final output of the controller and is the weighted average of the proper rule based outputs, which are selected by the back propagation algorithm.

\section{DEVELOPMENT OF SIMULINK MODEL}

Simulink model for the control of various parameters of the induction motor was developed in Matlab 7. This simulink model with the ANFIS controller was developed using the various toolboxes available in the simulink library such as the power system, power electronics, control system, signal processing toolboxes \& from its basic functions. The entire system modeled in Simulink is a closed loop feedback control system consisting of the plants, controllers, samplers, comparators, feedback systems, constants, buses, the mux, de-mux, summers, adders, gain blocks, multipliers, constant blocks, CT \& DT blocks, ANFIS editor blocks, clocks, sub-systems, integrators, state-space models, the output sinks (scopes), the input sources, work-space blocks, etc. The developed simulink model for the control of various parameters of the SCIM is shown in the Fig. 5. The specifications of the SCIM used for simulation purposes are given in the appendix. 


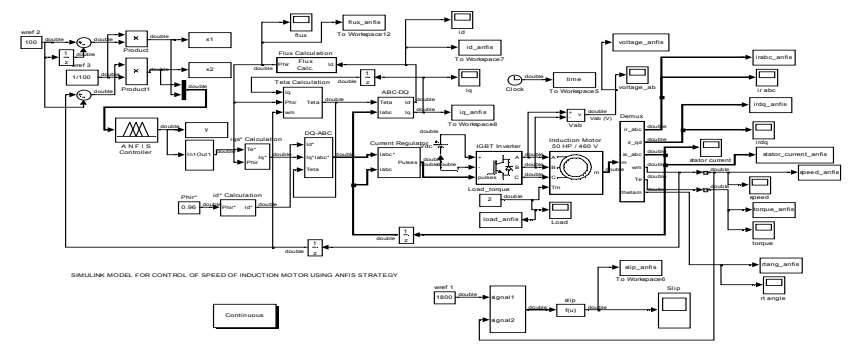

Fig. 5 : The developed simulink model for the speed control of IM's using neuro-fuzzy scheme (ANFIS)

\section{SIMULATION RESULTS \& DISCUSSIONS}

Simulink model with the neuro-fuzzy controller for the speed control of IM was developed in Matlab 7 as shown in the Fig. 5 above. In order to start the simulations, the 49 fuzzy rule set has to be invoked first from the command window in the Matlab. Initially, the fuzzy file where the rules are written with the incorporation of the T-S control strategy is opened in the Matlab command window, after which the fuzzy editor (FIS) dialogue box opens as shown in the Fig. 6 . The .fis file (sugenosevenrules2.fis) is imported using the command window from the source \& then opened in the fuzzy editor dialog box using the file open command. Once the file is opened, the TSfuzzy rules file gets activated as shown in the Fig. 7. Further, the data is exported to the workspace \& the simulations are run for a specific amount of time (say 3 secs). The fuzzy membership function editor is then obtained using the view membership command from the menu bar and this is shown in the Fig. 8. The written TS-fuzzy rules also can be viewed from the rule view command, which is presented in the Fig. 9. The rule viewer for the 2 inputs and 1 output can be observed pictorially in the Fig. 10. Now, after performing all the preliminary operations, the simulations are run for a period of 3 seconds in Matlab 7 with a reference speed of $100 \mathrm{rads} / \mathrm{sec}\{$ i.e., $(100 \times 60) / 2 \pi\}=955 \mathrm{rpm}$ $\&$ with a load torque of $2 \mathrm{~N}-\mathrm{m}$. Once, the simulation is run, the various parameters such as speed, flux, torque, currents, slip, voltage, etc. gets stored in the workspace.

After running the Takagi-Sugeno model, we get the error $(x 1)$, change in error $(x 2) \&$ an intermediate parameter $(y)$. These 3 parameters, viz., $x 1, x 2 \& y$ are stored in a variable in the command window. The 'anfis' editor is opened in the command window (Fig. 11). These variables which are in the form of data in the workspace are loaded into the 'anfis' editor (Figs. 12 \& 13). The .fis file is generated next in the 'anfis' editor by loading the data from the workspace (Fig. 14). Once the .fis file is generated, the 'anfis' has to be trained properly (Fig. 15) by selecting a proper algorithm with suitable number of epochs. In our work, we have used the back-propagation algorithm with a suitable number of epochs being used for training the rules. This is done by selecting these 2 items in the 'train window' of the 'anfis' editor \& training the neural network for proper selection of the rule base. The trained data is further exported to the workspace using the file-export command. The surface plot for the error speed \& change in error with the output is shown in the Fig. 16. Also, the contour plot of the same is depicted in the Fig. 17.
The developed ANFIS model structure with 2 input neurons \& 1 output neuron along with 4 hidden layers (input membership function, rule base, membership function, and aggregated output) are shown in the Fig. 18. The training of the neural network by using the fuzzy rule base for the selection of the proper $\&$ optimal rule is taken care of by the designed ANFIS controller. Note that 7 by 7 rules are used in the hidden layers. The neuron 1 is connected to 7 fuzzy rules $\&$ the neuron 2 is also connected to the 7 fuzzy rules. The hidden layers contains $49-49$ neurons to deal the problem (for selection of the proper rule base, because the rule base are written randomly in fuzzy, the neural network selects the right optimal rule base to fire). The 2 input neurons, viz., the error, change in error is given as input to the $1^{\text {st }}$ hidden layer of the ANN as shown in the Fig. 18. This $1^{\text {st }}$ hidden layer deals with various input membership functions. In the $2^{\text {nd }} \& 3^{\text {rd }}$ hidden layer, the set of 49 fuzzy rules are properly identified by training $\&$ the set of optimal rules are selected. These set of optimum rules are available at the $4^{\text {th }}$ hidden layer. Out of the 49 rules, the optimal rules are fired here $\&$ the de-fuzzified output is obtained as the output neuron. The de-fuzzified output is further used to generate the firing pulse to be applied to the inverter bridge, which is further used to control the speed of the IM drive.

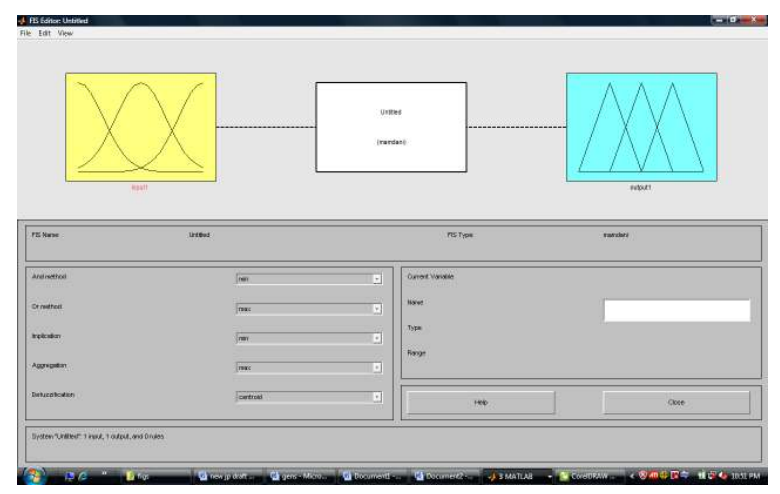

Fig. 6 : FIS editor with 1 input

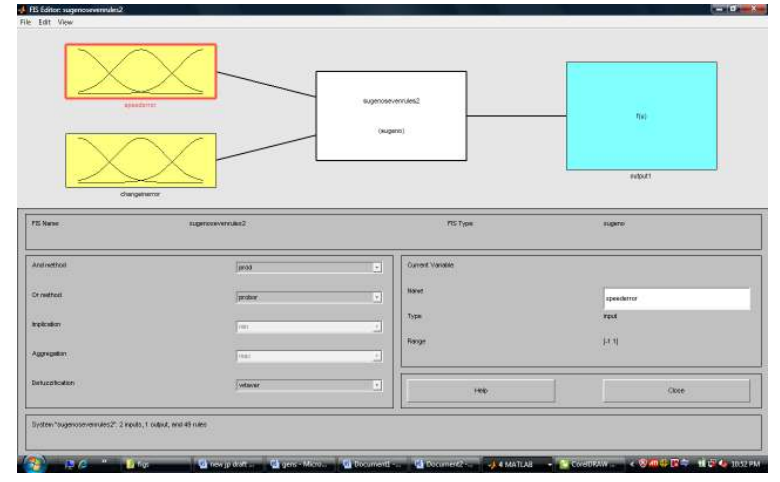

Fig. 7 : FIS editor with 2 inputs \& 1 output; Importing of the .fis file from the source 


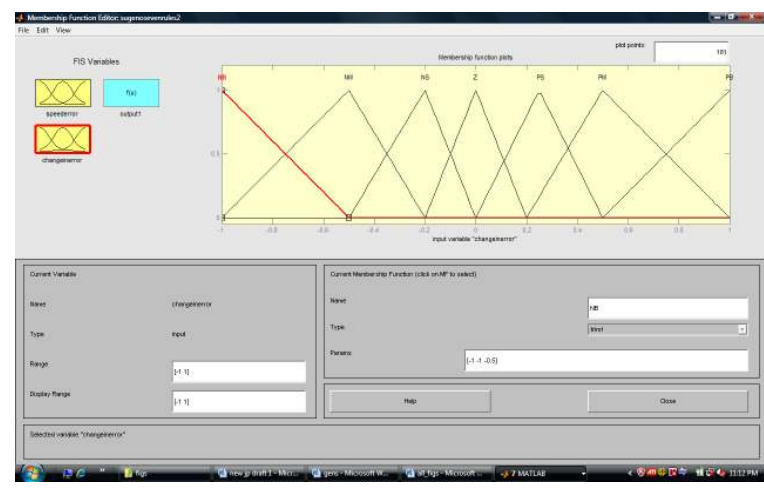

Fig. 8 : Membership function editor

After the simulation is run, the performance characteristics are observed on the respective scopes. The response curves of flux, load, torque, terminal voltage, speed, rotor angle, stator currents, slip, $i_{d}, i_{q}$, rotor currents $(3 \phi a b c \& d-q) \mathrm{v} / \mathrm{s}$ time, slip vs. speed for a reference speed of 100 rads / sec $(955 \mathrm{rpm}) \&$ with a load torque of $\mathbf{2} \mathbf{N}-\mathbf{m}$ are observed \& are shown in the Figs. 19 - 30 respectively.

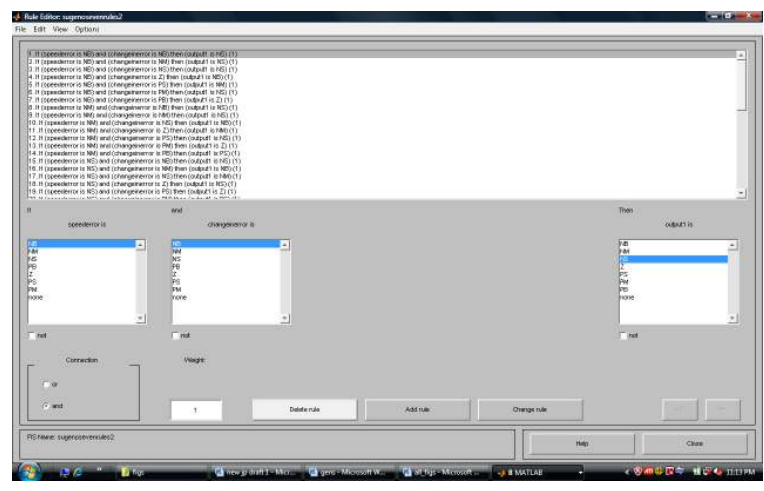

Fig. 9 : Rule editor window

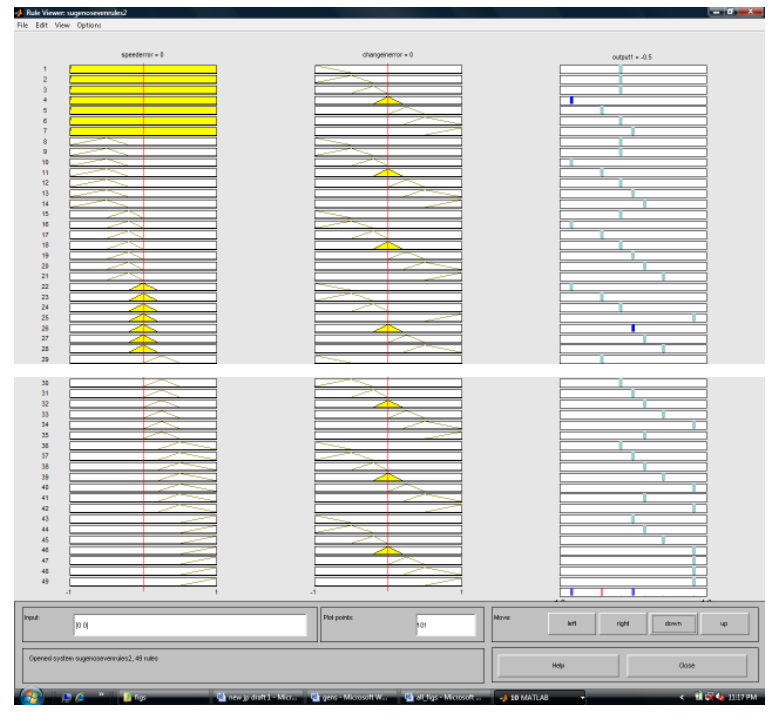

Fig. 10 : Rule viewer window

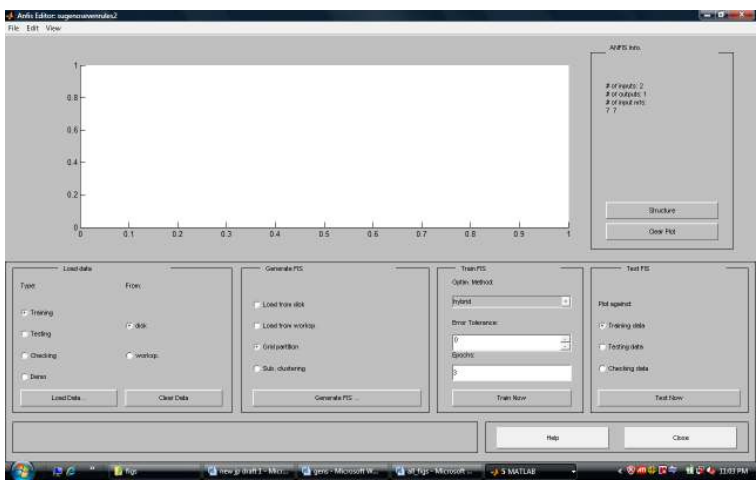

Fig. 11 : ANFIS editor window

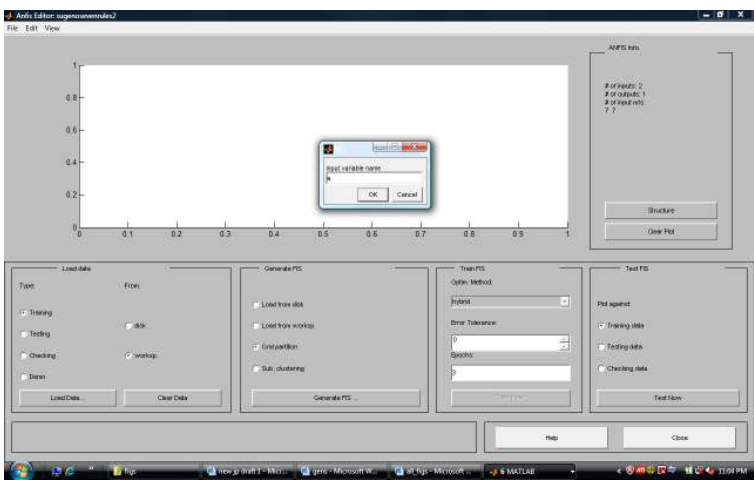

Fig. 12 : ANFIS editor : Loading the data from the workspace

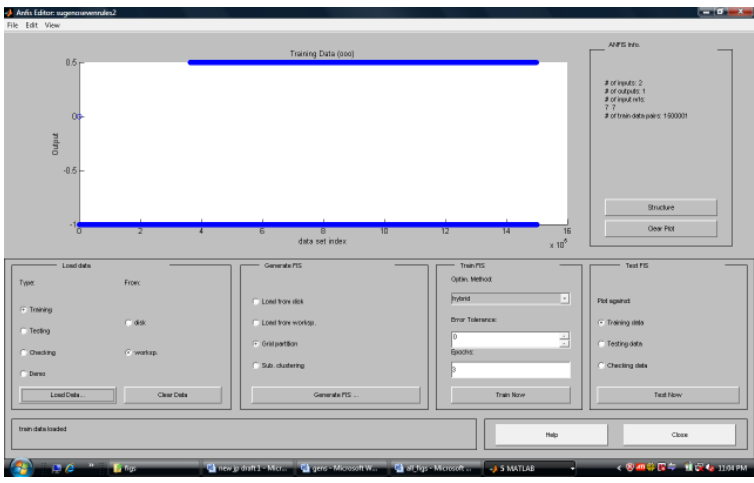

Fig. 13 : ANFIS editor : Loaded data from the workspace onto the editor

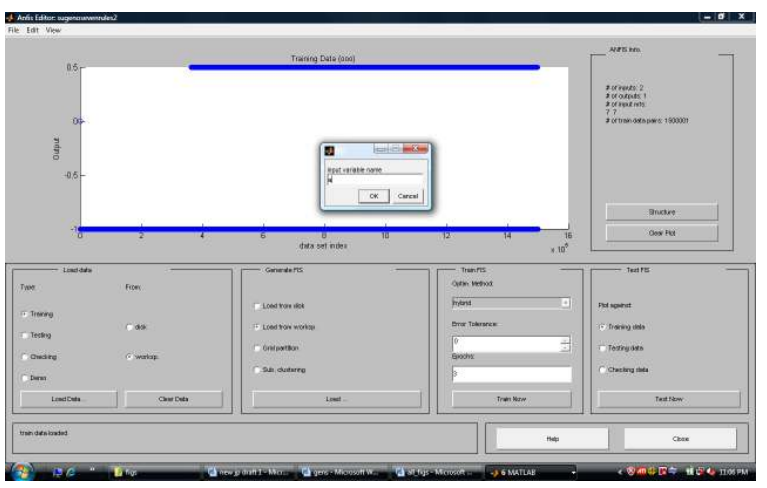

Fig. 14 : ANFIS editor : Generate the FIS file from the data in the workspace 
From the simulation results shown in the Figs. 19 to 30 , it is observed that the stator current does not exhibit any overshoots nor undershoots. The response of the flux, slip, torque, terminal voltage, speed, currents, etc. takes lesser time to settle \& reach the desired value compared to the results presented in [3], [4], [5].

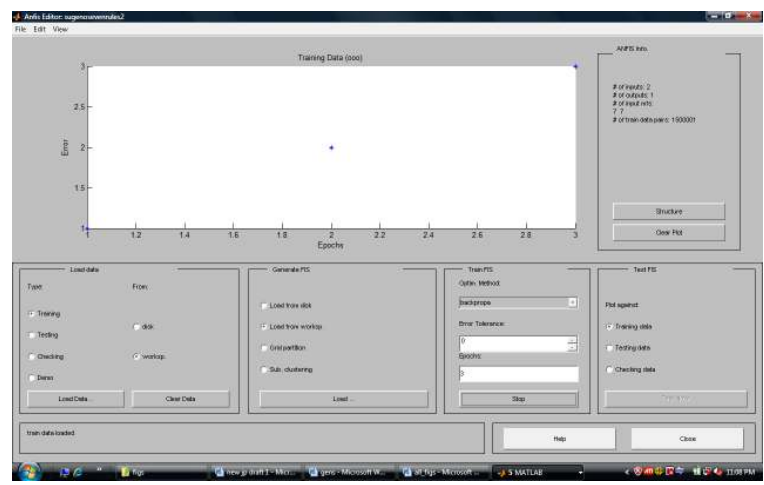

Fig. 15 : ANFIS editor : Training the rules using backpropagation algorithm

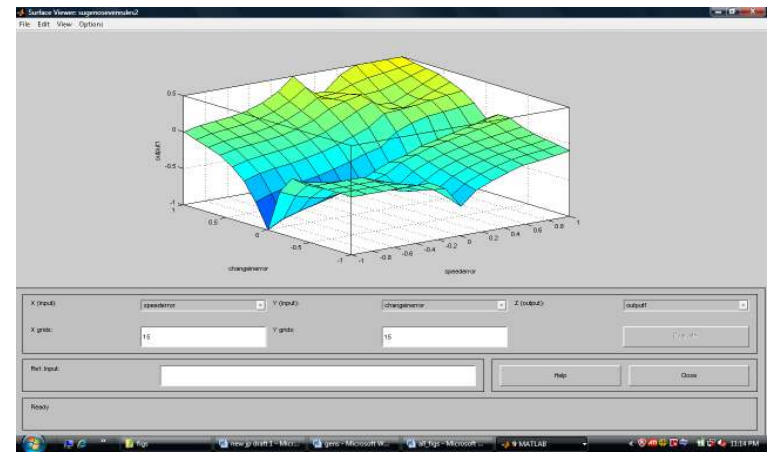

Fig. 16 : Surface plot of the 3 parameters ( 2 inputs : change in error, speed error \& 1 output)

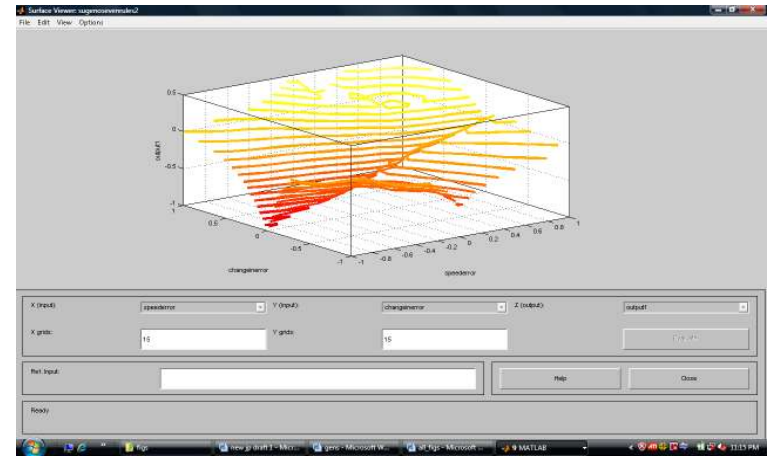

Fig. 17 : Contour plot of the 3 parameters ( 2 inputs : change in error, speed error \& 1 output)

It was observed from the simulation results that by using the neuro-fuzzy (ANFIS) control, for the set speed of $100 \mathrm{r} / \mathrm{s} \&$ for the 49 rules, the speed reaches its desired set value at 0.44 seconds. This shows the effectiveness of the designed neurofuzzy controller $\&$ the designed neuro-fuzzy controller tries to speed up the performance of the drive, thus showing faster dynamism. It is also observed that with the designed neuro-fuzzy controller, the response characteristics curves take less time to settle \& reach the final steady state value compared to that in [3], [4], [5]. The motor speed increases like a linear curve upto the set speed of $955 \mathrm{rpm}(100 \mathrm{r} / \mathrm{s})$ in 0.44 secs as shown in Fig. 30. Further, it can also be observed that using the ANFIS control, the system stabilizes in a very less time compared to the other methods because of the training process of the ANN involved \& the proper selection of the rule base.

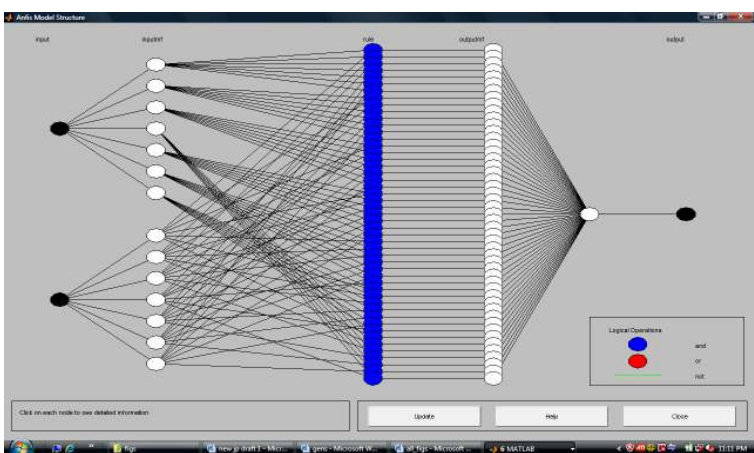

Fig. 18 : ANFIS model structure with 2 inputs \& 1 output showing all the 5 layers in the ANN architecture

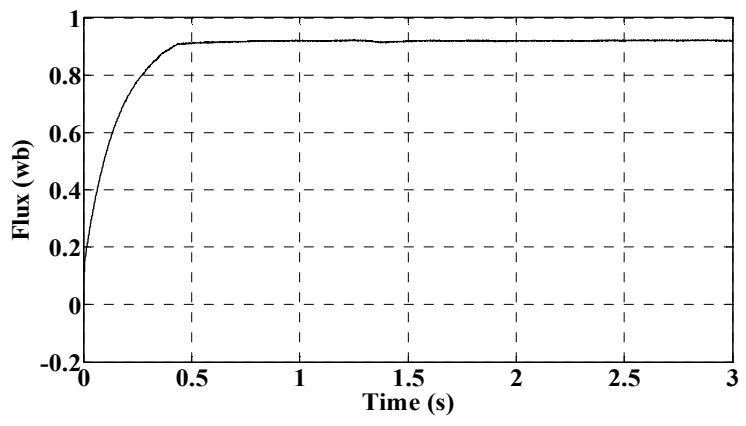

Fig. 19 : Plot of flux vs. time

From the variation of flux with time as shown in the Fig. 19, it can be observed that when the motor speed is increasing (during the transient period), more stator current is required to develop the requisite flux in the air gap. Hence, the flux also starts increasing during the transient period ( 0 to $0.4 \mathrm{sec}$ ) exponentially. Once, the motor attains the set rated speed, the flux required to develop the torque almost remains constant after $\geq 0.4$ secs. Once, the flux in the air gap remains constant, the variation of the load torque and speed will not disturb the flux curve. Hence, the IM will be operating at a constant flux.

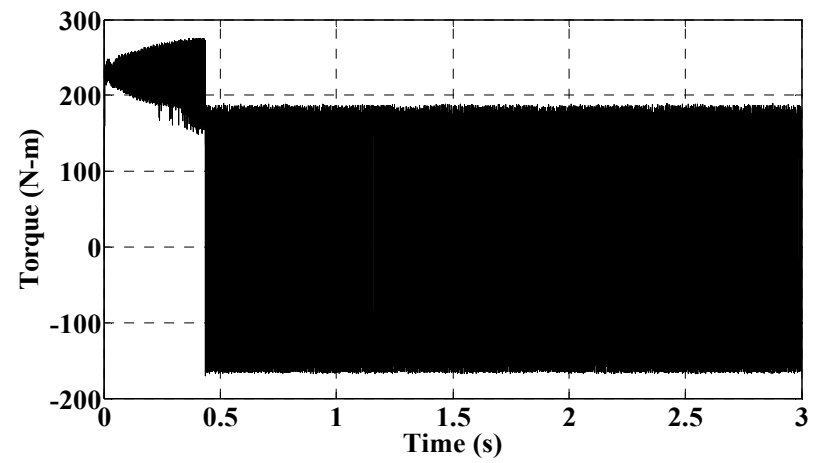


Fig. 20 : Plot of torque vs. time

Torque characteristics for a set reference speed of $100 \mathrm{r} / \mathrm{s}(955$ $\mathrm{rpm}$ ) is shown in the Fig. 20. From this figure, we arrive at a conclusion that when the motor is operating at lower speeds, the slip is more. Hence, the machine requires more torque to attain the set speed. Once the machine reaches the set speed of $955 \mathrm{rpm}$ the average torque of the machine becomes nearly zero after 0.44 $\mathrm{s}$, which is justified from the simulation result in Fig. 21. The terminal voltage of the IM is shown in Figs. 21 (a) \& (b) respectively.
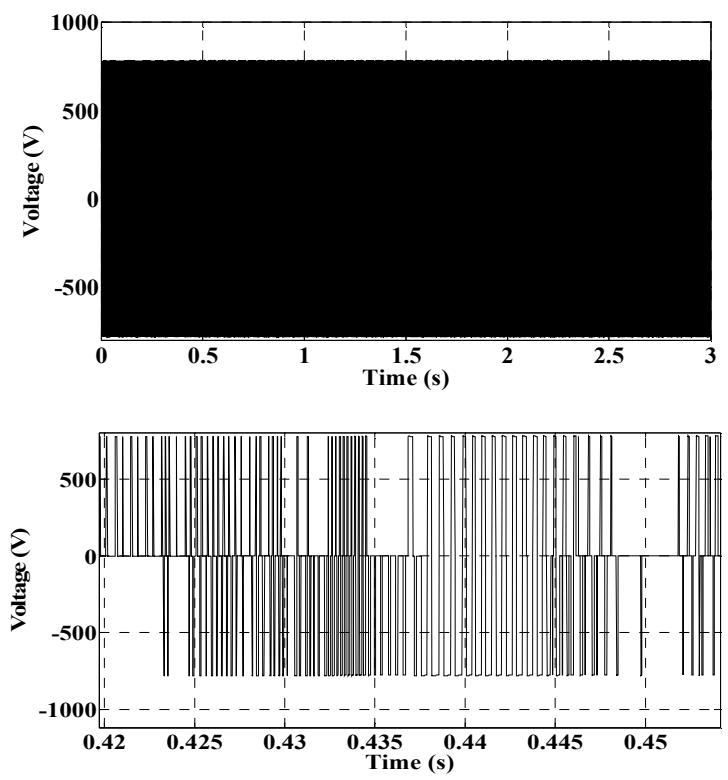

(a) Plot of voltage vs. time (normal) (b) Plot of voltage vs. time (zoomed) between $t=0.42 \mathrm{~s}$ to $0.45 \mathrm{~s}$

Fig. 21 : Plot of voltage vs. time (normal \& zoomed)

The variation of the $3 \phi$ stator currents $\left(i_{s}\right)$ with time is shown in the Fig. 22. It can be clearly observed from this figure, that at lower speeds, the slip is more, the flux required to develop the suitable torque is also more. Also, the torque required to reach the set speed is also more. Hence, the magnitude of the stator currents will also be more during the transient periods (starting periods) of the induction motor. When the speed is reaching the set value from zero, the $3 \phi$ stator currents decreases exponentially. Once, it attains the set speed at 0.44 secs, it requires a nominal stator current to drive the IM system.

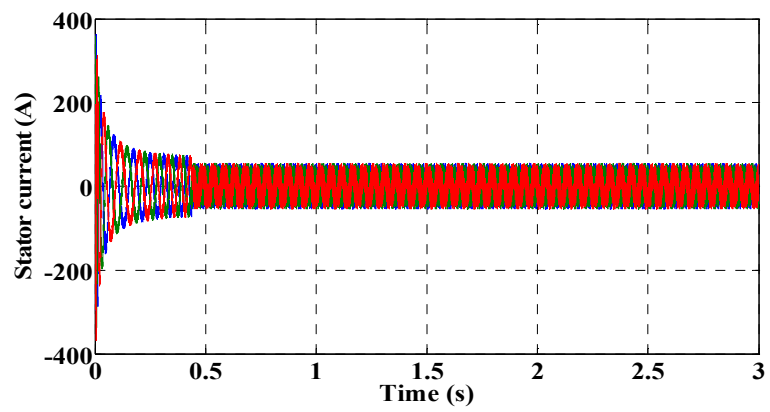

Fig. 22 : Plot of $3 \phi$ stator current vs. time
The Fig. 23 shows the variation of slip vs. time characteristics for a speed of $100 \mathrm{r} / \mathrm{s}(955 \mathrm{rpm})$. From this simulation result, we infer that the IM attains the set reference speed of $955 \mathrm{rpm}$ in 0.44 secs using the ANFIS (neuro-fuzzy) controller. At that instant, the slip being $\frac{N_{s}-N}{N_{s}}=\frac{1800-955}{1800}=0.46$, can be verified from the result shown. Note that the slip decreases from 1.0 to 0.46 linearly in a time span of just 0.44 secs.

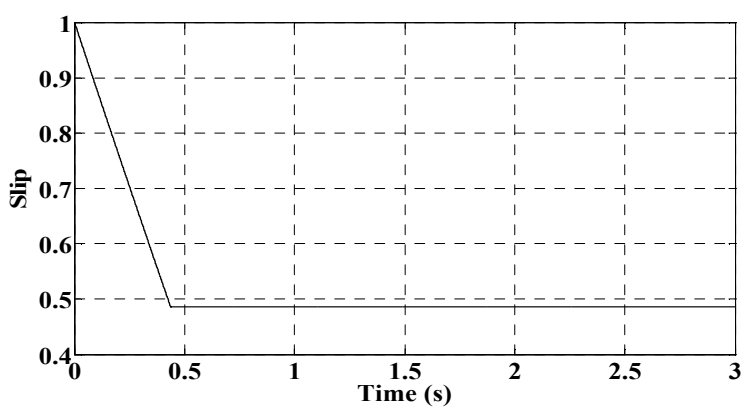

Fig. 23 : Plot of slip vs. time

The slip-speed characteristics is shown in the Fig. 24. It can be noted that when the speed is varied from 0 to the rated speed, the slip decreases, i.e., the slip is inversely proportional to the speed, which is the property of the IM. When the speed is zero, the slip is $100 \%$, while the IM is operating at near the rated speed $(180 \mathrm{r} / \mathrm{s})$, the slip is very very low.

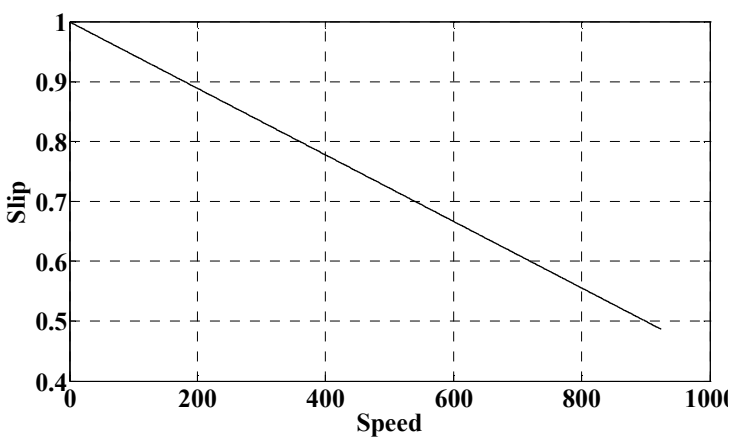

Fig. 24 : Plot of slip vs. speed

The plots of the direct axes $\left(i_{d}\right) \&$ quadrature axes currents $\left(i_{q}\right)$ versus time is shown in the Figs. $25 \& 26$ respectively. From these figures, it can be inferred that the machine reaches the set reference speed of $955 \mathrm{rpm}$ in a time interval of $0.44 \mathrm{secs}$.

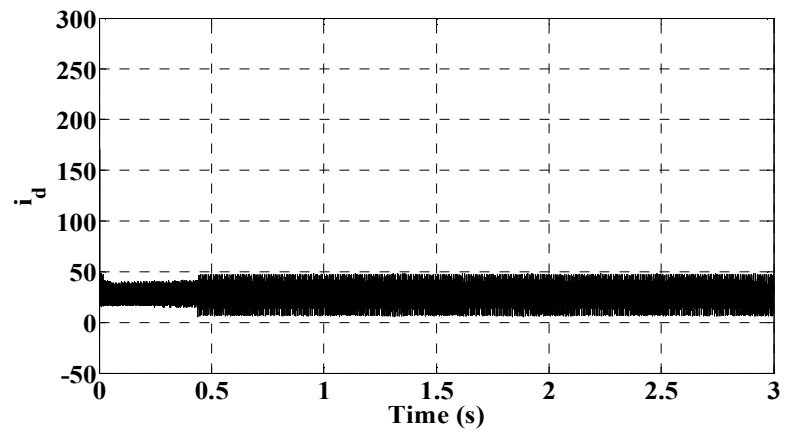

Fig. 25 : Plot of $i_{d}$ vs. time 


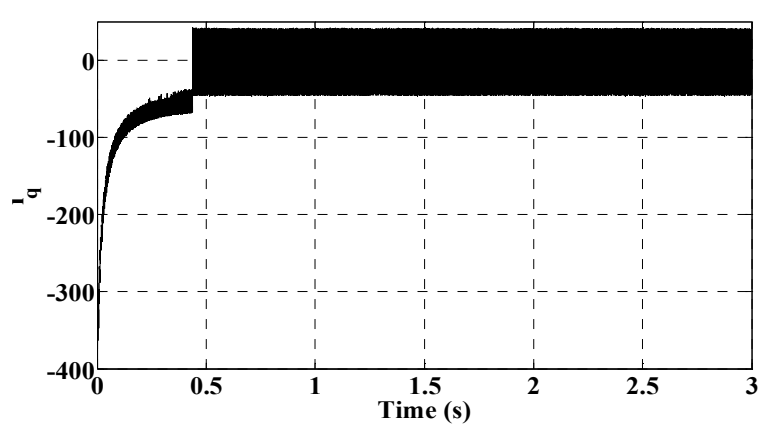

Fig. 26 : Plot of $i_{q}$ vs. time

The variation of the $3 \phi$ rotor currents $\left(i_{r}-a b c\right)$ with time is shown in the Fig. 27. It can be inferred that at lower speeds, the slip is more, the flux required to develop the suitable torque is also more. Also, the torque required to reach the set speed is also more. Hence, the magnitude of the rotor currents will also be more during the transient periods (starting periods) of the induction motor. When the speed is reaching the set value from zero, the $3 \phi$ rotor currents decreases exponentially upto 0.44 secs, thereafter it is maintained constant.

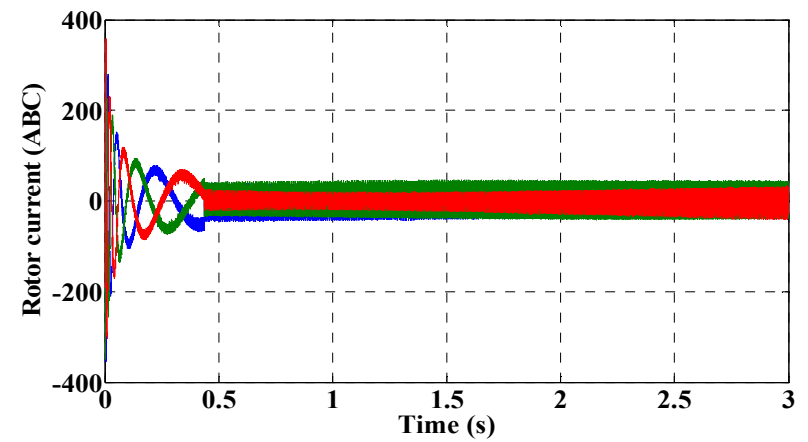

Fig. 27 : Plot of rotor current $i_{r a b c}$ vs. time

The $3 \phi$ rotor currents $\left(i_{r}-\mathrm{abc}\right)$ is transformed to direct axes $\&$ quadrature axes currents using the $d-q$ transformation techniques and the variation of the transformed currents with time is shown in the Fig. 28. Here, only two phases ( $d \& q$ axes) of the currents can be observed in the characteristic curve. In this case, also, once the motor achieves the the set speed at $0.44 \mathrm{secs}$, it requires a nominal current to drive the IM system. The plot of rotor angle vs. time is shown in the Fig. 29.

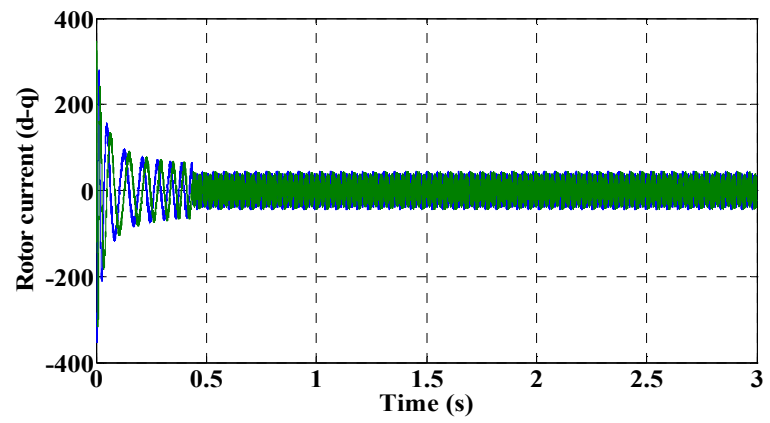

Fig. 28 : Plot of rotor current $i_{r d q}$ vs. time

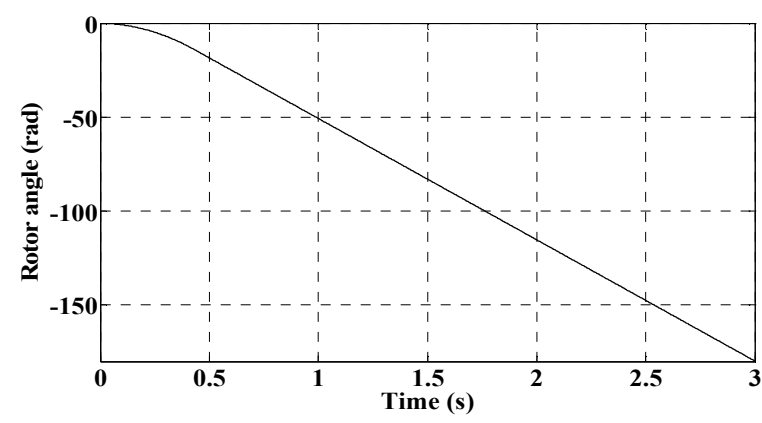

Fig. 29 : Plot of rotor angle vs. time

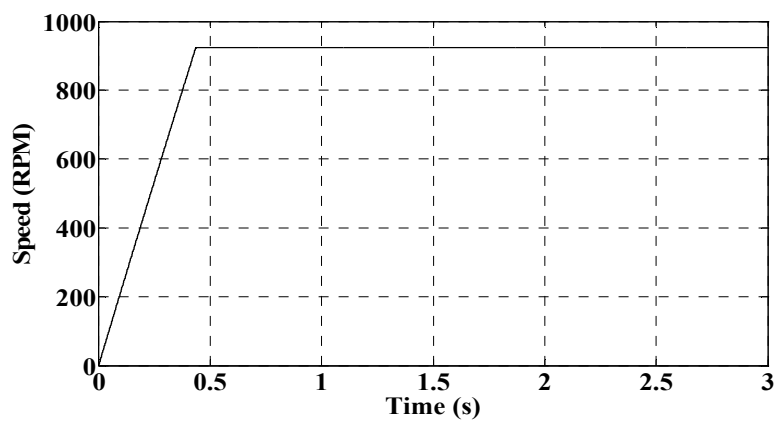

Fig. 30 : Plot of speed vs. time

To sum up, the steps required for the simulation purposes can be shown in the form of an data flow diagram (DFD) as follows :

(1) Start

(2) Invoke the fuzzy editor

(3) Load the fis file

(4) Export the .fis file to WS

(5) Run the TS model

(6) Stop the TS simulation

(7) Select variables $x 1, x 2, y$

(8) Open anfis editor

(9) Load variables from WS

(10) Generate .fis file from WS

(11) Train using BP algo method

(12) Select suitable no. of epochs

(13) Train the ANN

(14) Export the data to WS

(15) Run the ANFIS model

(16) Stop the ANFIS simulation

(17) Observe performance characteristics

(18) Stop

\section{CONCLUSIONS}

A systematic approach of achieving the speed control of an induction motor drive by means of adaptive neuro fuzzy inference control strategy has been investigated in this paper. Simulink model was developed in Matlab 7 with the ANFIS controller for the speed control of IM. The control strategy was also developed by writing a set of 49 fuzzy rules according to the ANFIS control strategy with the back propagation algorithm in the back end. The main advantage of designing the ANFIS coordination scheme is to control the speed of the IM \& to increase the dynamic performance \& to provide good stabilization. Simulations were run in Matlab $7 \&$ the results were observed on the corresponding 
scopes. The characteristic curves of speed, torque, current, flux, slip, load, etc. vs. time were observed. The outputs take less time to stabilize, which can be observed from the simulation results. Due to the incorporation of the ANFIS controller in loop with the plant, it was observed that the motor reaches the rated speed very quickly in a lesser time compared to the Mamdani method [3].

The main advantages of the ANFIS scheme being, it is computationally efficient, works well with linear techniques, optimization \& adaptive techniques. The developed control strategy is not only simple, but also reliable and may be easy to implement in real time applications using some interfacing cards like the dSPACE, data acquisition cards, TMSDSP cards, NI cards, etc. for control of various parameters. This can also be combined with expert systems \& rough sets for other applications. The ANFIS also can be used with systems handling more complex parameters. Another advantage of the ANFIS being the speed of operation of ANFIS is much faster than the other control strategies; the tedious task of training of membership functions is done in ANFIS. Collectively, these results show that the ANFIS controller provides faster settling times, has very good dynamic response \& good stabilization compared to the Mamdani-fuzzy control scheme [3].

\begin{tabular}{ll} 
& \multicolumn{1}{c}{ Abbreviations } \\
AC & Alternating Current \\
AI & Artificial Intelligence \\
ANFIS & Adaptive Neuro Fuzzy Inference System \\
ANN & Artificial Neural Networks \\
BP & Back Propagation \\
DC & Direct Current \\
DSP & Digital Signal Processor \\
DTC & Direct Torque Control \\
DOF & Degree Of Freedom \\
FIS & Fuzzy Inference System \\
FLC & Fuzzy Logic Controller \\
FNN & Fuzzy Neural Networks \\
FOC & Field Oriented Control \\
IM & Induction Motor \\
IEEE & Inst. of Elect. \& Electronics Engg. \\
MRAC & Model Reference Adaptive Control \\
MF & Membership Function \\
Matlab & Matrix Laboratory \\
NN & Neural Network \\
NI & National Instruments \\
PI & Proportional Integrator \\
PD & Proportional Derivative \\
PID & Proportional Integral Derivative \\
PWM & Pulse Width Modulation \\
SCIM & Squirrel Cage Induction Motor \\
SMC & Sliding Mode Control \\
SVPWM & Space Vector Pulse Width Modulation \\
TS & Takagi Sugeno \\
&
\end{tabular}

\section{Nomenclatures \& Symbols}

$\begin{array}{ll}\phi & \text { Phase } \\ s & \text { Laplace domain } \\ z & \text { Discrete domain } \\ d & \text { Direct axis variable } \\ q & \text { Quadrature axis variable }\end{array}$

$V_{s d} \quad$ Direct axis stator voltage

$V_{s q} \quad$ Quadrature axis stator voltage

$V_{r d} \quad$ Direct axis rotor voltage

$V_{r q} \quad$ Quadrature axis rotor voltage

$i_{s d} \quad$ Direct axis stator current

$i_{s q} \quad$ Quadrature axis stator current

$i_{r d} \quad$ Direct axis rotor current

$i_{r q} \quad$ Quadrature axis rotor current

$\phi_{\text {sd }} \quad$ Direct axis stator flux linkages

$\phi_{\text {rd }} \quad$ Quadrature axis stator flux linkages

$\phi_{\mathrm{sd}} \quad$ Direct axis rotor flux linkages

$\phi_{\text {sd }} \quad$ Quadrature axis rotor flux linkages

$t \quad$ Time

$L_{r} \quad$ Rotor inductance

$L_{s} \quad$ Stator inductance

$L_{m} \quad$ Mutual inductance

$\omega \quad$ Angular frequency

$T_{e m} \quad$ Electromagnetic torque

$P \quad$ Power

$T_{L} \quad$ Load torque

$J_{e q} \quad$ Equivalent Moment of Inertia

$V_{m} \quad$ Maximum value of AC voltage

$V_{A n} \quad$ Voltage of phase-A to neutral

$V_{B n} \quad$ Voltage of phase-B to neutral

$V_{C n} \quad$ Voltage of phase-C to neutral

$V_{D C} \quad$ DC voltage

\section{Appendix}

A1. Squirrel Cage Induction Motor (SCIM) specs :

$50 \mathrm{HP}, 1800 \mathrm{rpm}, 460 \mathrm{~V}, 60 \mathrm{~Hz}$., 3-Phase

2 pair of poles, Squirrel Cage type IM

$R_{s}=0.087 \Omega, L_{s}=0.8 \times 10^{-3} \mathrm{H}$

$R_{r}=0.228 \Omega, L_{r}=0.8 \mathrm{mH}$

$L_{m}=34.7 \mathrm{mH}$

$J=1.662 \mathrm{~kg} \cdot \mathrm{m}^{2}$

\section{REFERENCES}

[1]. A.Iqbal, "Analysis of space vector pulse width modulation for a five phase voltage source inverter" IE (I) journal-EL, Vol. 89, Issue 3, pp. 8-15, Sept. 2008.

[2]. Allouche Moez, Souissi Mansour, Chaabane Mohamed and Mehdi Driss, "Takagi-Sugeno Fuzzy Control of Induction Motor", Proc. Int. Journal of Electrical and Electronics Engg., Vol. 2, Issue 1, 2009.

[3]. Ashok Kusagur, S. F. Kodad, B V. Sankar Ram, "AI based design of a fuzzy logic scheme for speed control of induction motors using SVPWM technique", Int. Jr. Comp. Sci. \& Network Security, Vol. 9, No. 1, pp. 74 80, Jan. 2009.

[4]. Ashok Kusagur, S.F.Kodad, B.V. Sankar Ram, "Modelling of Induction Motor \& Control of Speed Using Hybrid Controller Technology", Proc. Int. Journal of Theoretical Information \& Technology (JATIT), Vol. 10, issue 2, pp. 117-126, Dec. 2009, 
[5]. Ashok Kusagur, S.F.Kodad, B.V. Sankar Ram, "Novel design of a Takagi-Sugeno fuzzy strategy for induction motor speed control", Paper accepted for publication in Journal of Electrical Systems, Vol. 6, issue 2, Jun. 2010.

[6]. Ashok Kusagur, Jagadish Pujar, "Design of A VAR Compensator", Proc. International Conference on Trends in Intelligent Electronic Systems, Satyabhama University, Chennai, Tamil Nadu, India, Nov. 12 - 14, 2007.

[7]. Aware M.V., Kothari A.G., Choube S.O., "Application of adaptive neuro-fuzzy controller (ANFIS) for voltage source inverter fed induction motor drive", The Third International_Electronics and Motion Control Conference - IPEMC 2000, Vol. 2, pp. 935-939, 2000.

[8]. Barrero F., A. Gonziilez, A. Torralba, E. GalvBn and L.G. Franquelo, "Speed Control of Induction Motors Using a Novel Fuzzy-Sliding Mode Structure", IEEE Conf. paper, pp. 1073-1078.

[9]. Ben-Brahim L., "Improvement of the stability of the V/f controlled induction motor drive systems", IEEE Proceedings of the $24^{\text {th }}$ Annual Conference, Vol. 2, pp. 859-864, 1998.

[10]. Bimal K Bose, Nitin R Patel, Kaushik Rajashekara, “A neuro-fuzzy based on-line efficiency optimization control of a stator flux oriented direct vector controller IM drive", IEEE Trans. Industrial Electronics, Vol. 44, No. 2, pp. 270-273, Apr. 1997.

[11]. Bose B.K., Modern Power Electronics and AC Drives, Pearson Education, Inc., India, 2002.

[12]. Cao S.G., Rees N.W. and Feng G., "Analysis and design of fuzzy control systems using dynamic fuzzy state space Models", Proc. of the Trans. on IEEE Trans. Fuzzy Syst., Vol. 7, No. 2, pp. 192-199, 1999.

[13]. Carlos A. Martins, Adriano S. Carvalho, "Technological Trends in Induction Motor Electrical Drives", IEEE Porto Power Tech Conference, Vol. 2, Sep. 2001.

[14]. Chen C-Li and Chang M-Hui, "Optimal design of fuzzy sliding mode control: A comparative study", Fuzzy Sets Syst., Vol. 93, pp. 37-48, 1998.

[15]. Chen J.Y. and C.C. Wong, "Implementation of the TakagiSugeno model-based fuzzy control using an adaptive gain controller", IEE Proc. - Control Theory Appl., Vol. 147, No. 5, pp. $509-514$, Sept. 2000.

[16]. Chen T.C., and Hsu J.U., "A fuzzy sliding mode controller for induction motor position control", IECON'94., 20th Int. Conf on Industrial Electronics, Control and Instrumentation, Vol. 1, pp. 44-49, 1994.

[17]. Chong. Lin, Q.G. Wang and T.H. Lee, "Output tracking control for nonlinear via T-S fuzzy model approach, Proc. IEEE Trans. systems. Cybernetics, Vol. 36, No. 2, 2006.

[18]. Chuen Chien Lee, "Fuzzy Logic in Control Systems : Fuzzy Logic controller -Part 2", IEEE, 1990.

[19]. Chuen Chien Lee, "Fuzzy Logic in Control Systems: Fuzzy Logic controller-Part 1", IEEE, 1990.

[20]. Consoli A, E. Cerruto, A. Raciti, A. Testa, "Adaptive vector control of induction motor drives based on a neuro fuzzy approach”, IEEE Paper, pp. 225-232, 1994.
[21]. Ernesto Araujo, "Improved Takagi-Sugeno Fuzzy Approach", IEEE International Conference on Fuzzy Systems (FUZZ 2008), pp. 1154-1158, 2008.

[22]. Faa Jeng Lin, Rong Jong Wai, “Adaptive fuzzy neural network control for IM spindle motor drive", IEEE Trans. Energy Conversion, Vol. 17, No. 4, pp. 507-513, Dec. 2002.

[23]. Farzan Rashidi, "Sensorless Speed Control of Induction Motor Derives Using a Robust and Adaptive Neuro-Fuzzy Based Intelligent Controller", IEEE International Conference an Industrial Technology (ICIT), pp. 617-627, 2004.

[24]. Giovanna Castellano, "A neuro-fuzzy methodology for predictive modelling”, Ph.D. Thesis, Dept. of Comp. Sci., Univ. of Bari, 2000.

[25]. Grabowski, P.Z. Kazmierkowski, M.P. Bose, B.K. Blaabjerg, F. , "A simple direct-torque neuro-fuzzy control of PWM-inverter-fed induction motor drive", IEEE Trans. on Industrial Electronics, Vol. 47, Issue 4, pp. 863 - 870, Aug 2000.

[26]. H. Rehman and R. Dhaouadi, "A fuzzy learning-sliding mode controller for direct field-oriented induction machinese", Neuro-computing, Vol. 71, pp. 2693-2701, 2008.

[27]. Haider A. F. Mohamed, E. L. Lau, S. S. Yang, M. Moghavvemi, "Fuzzy-SMC-PI Flux and Speed Control for Induction Motors", Proc. of RAM-2008, pp. 325-328, 2008.

[28]. Hassan Baghgar Bostan Abad, Ali Yazdian Varjani, Taheri Asghar, "Using Fuzzy Controller in Induction Motor Speed Control withConstant Flux", Proc. of world academy of science, engineering and technology, Vol. 5, ISSN 1307-6884, April 2005.

[29]. Henrik Mosskull, Johann Gali'c, and Bo Wahlberg, "Stabilization of Induction Motor Drives With Poorly Damped Input Filters", IEEE Transactions on Industrial Electronics, Vol. 54, No. 5, pp. 2724-2734, Oct. 2007.

[30]. http://www.wikipedia.org

[31]. Iman Zamani, Masoud Shafie, "Fuzzy Affine Impulsive Controller”, Fuzzy IEEE 2009, Korea, pp. 361-366, Aug. 20-24, 2009.

[32]. Jagdish Pujar, Ashok Kusagur, S.F. Kodad, T.C. Manjunath, "Fuzzy Logic Based Flexible Multi-Bus Voltage Control of Power Systems", Proc. of the $31^{s t}$ National Systems Conference, NSC-2007, MIT-MAHE Campus, Manipal - 576104, Karnataka, India, 14-15, Nov. 2007.

[33]. Jinjie Huang, Shiyong Li, Chuntao Man, "A TS type of fuzzy controller based on process of input output data", Proc. of $42^{\text {nd }}$ IEEE Conf. on Decision \& Control (CDC'03), Hawai, USA, pp. 4729-4734. Dec. 2003.

[34]. Kazuo Tanaka, Hua O. Wang, "Fuzzy Control Systems Design and Analysis: A Linear Matrix Inequality Approach" John Wiley \& Sons, Inc., USA. 2002.

[35]. Khiar D., "Robust takagi-sugeno fuzzy control of a spark ignition engine", Control Engg. Practice, 2007.

[36]. Kim D.H., Kim H.S., Kim J.M., Won C.Y. and Kim S.C., "Induction motor servo system using variable structure control with fuzzy sliding surface", IEEE Int. Conf. 
Industrial Electronics, Control, and Instrumentation, Vol. 2, pp. 977-982, 1996.

[37]. Liu X., and S. Zhong, "T-S fuzzy model-based impulsive control of chaotic systems with exponential decay rate", Physics Letters A, Vol. 370, pp. 260-264, 2007.

[38]. M. Sugeno and K. Tanaka, "Successive identification of a fuzzy model and its applications to prediction of a complex system", Proc. Fuzzy Sets and Systems, Vol. 42, pp. 315-334, 1992.

[39]. Mihoub M, B. Mazari, S. Fasla, "Neuro-fuzzy controller used to control the speed of an induction motor", Conference paper.

[40]. Mir. S.A and Malik. E. Elbuluk, "Fuzzy controller for Inverter fed Induction Machines", IEEE Transactions on Industry Applications, Vol. 30, pp. 78-84, 1994.

[41]. Mokhtar Zerikat, Sofiane CHekroun, "High performance speed tracking of IM using an adaptive fuzzy NN control", Int. Jr. Sciences \& Techniques of Auto. Contr. \& Computer Engg., IJ-STA Special Issue, CEM, pp. 516531, Dec. 2008.

[42]. Mouloud Azzedine Denai, Sid Ahmed Attia, "Fuzzy and Neural Control of an Induction Motor", Proc. Int. J. Appl. Math. Comput. Sci., Vol.12, No. 2, pp. 221-233, 2002.

[43]. Nasir Uddin M., Hao Wen, "Model Reference Adaptive Flux Observer Based Neuro-Fuzzy Controller for Induction Motor Drive", IAS-2005, IEEE paper, pp. 1279 -1285 .

[44]. Peter Vas, "Sensorless Vector and Direct Torque control", Oxford University press, 1998.

[45]. R. Arulmozhiyal, K. Baskaran, "Space Vector Pulse Width Modulation Based Speed Control of Induction Motor using Fuzzy PI Controller", Proc. of the International Journal of Computer and Electrical Engg., Vol. 1, No. 1, pp. 98-103, April 2009.

[46]. Ramón C. Oros, Guillermo O. Forte, Luis Canali, "Scalar Speed Control of a $d-q$ Induction Motor Model Using Fuzzy Logic Controller", Conf. paper.

[47]. Satean Tunyasrirut, Tianchai Suksri, and Sompong Srilad, "Induction Motor using Space Vector Pulse Width Modulation", Proc. of the World Academy of Science, Engineering Fuzzy Logic Control for a Speed Control of And Technology, Vol. 21, pp. 71 - 77, Jan. 2007.

[48]. Shaw A. and Doyle F., "Multivariable non-linear control application for a high purity distillation column using a recurrent dynamic neuron model", $J$. Process Contr., Vol. 7, No. 4, pp. 255-268, 1997.

[49]. Sivanandam S.N., S. Sumathi and S.N. Deepa, "Introduction to fuzzy logic using Matlab", SpringerVerlarg Publications, 2007.

[50]. Sugeno M. and G. T. Kang, "Structure identification of fuzzy model", Proc. on the Fuzzy Sets and Systems, Vol. 28, pp. 15-33, 1988.

[51]. Takagi T. and M. Sugeno, "Fuzzy identification of system and its applications to modeling and control", Proc. IEEE Trans. on System Man and Cybernetics, Vol. SMC-15, No. 1, pp. 116-132, 1985.
[52]. Trzynadlowski A.M., "The Field Orientation Principle in Control of Induction Motors", Kluwer Pub., Dordrecht, 1994.

[53]. Vas P., "Vector Control of AC Machines", Oxford University Press, London, UK, 1990.

[54]. Xie Keming, TY Lin, Zhang Jianwei, "The Takagi-Sugeno fuzzy model identification method of parameter varying systems", Proc. Rough Sets Current Trends Conf., RSCTC'98, Warsaw, Poland, Jun. 22-26, 1998.

[55]. Yasuhiko Dote, Yuji Fujino, Amin Suyitno, "Neuro fuzzy robust controllers for AC drive systems", IEEE Conf. paper, pp. 2311-2316, 1993.

[56]. Yu Zhang, Zhenhua Jiang, Xunwei Yu, "Indirect FieldOriented Control of Induction Machines Based on Synergetic Control Theory", IEEE Int. Conf. on Power and Energy Society General Meeting - Conversion and Delivery of Electrical Energy in the 21st Century, 2008, pp. 20-24, 1 - 7, Jul. 2008.

[57]. Zdenko Kovaccic and Stjepan Bogdan, "Fuzzy Controller design Theory and Applications", Taylor \& Francis Group International, 2002.

[58]. Zhang X., et. al., "Impulsive stability of chaotic systems represented by T-S model", Proc. Chaos, Solutions \& Fractals, doi:10.1016/j.chaos.2008.07.052, 2008.

\section{AUTHOR PROFILE}

Ashok Kusagur was born in the year 1970 and he received the B.E. degree in Electrical \& Electronics Engg. (EEE) from Bapuji Institute of Engg. \& Tech. (BIET), Davanagere, Karnataka, India from Kuvempu University in the year 1996 and the M.Tech. Degree in Power Electronics from PDA College of Engg., Gulbarga, Karnataka, India from the VTU in the year 2001. He has got a teaching experience of nearly 12 years. Currently, he is working as Professor \& Head of the Department of Electronics \& Communications Engg. in HMS Institute of Technology, Tumkur, Karnataka, India in the Dept. of Electronics \& Communications Engg. \& simultaneously doing his Ph.D. (Research) in Electrical \& Electronics Engg. from the prestigious Jawaharlal Nehru Technological University (JNTU), Hyderabad, Andhra Pradesh, India. He has published more than a number of papers in various national \& international conferences \& journals. His areas of interests are neural networks, fuzzy logic, artificial intelligence, power electronics, field theory, networks, control systems, Matlab, etc.

Dr. S. F. Kodad received the B.E. degree in EEE from STJ Institute of Technology, Ranebennur, Karnataka, India from Karnataka University and the M.Tech. degree in Energy Systems Engg. from JNTU, Hyderabad, India in the year 1992. He received his Ph.D. degree in Electrical Engg. from JNTU, Hyderabad, India in the year 2004. He has got a teaching experience of nearly 20 years. Currently, he is working as Director in Krishnamurthy Institute of Technology, Hyderabad, Andhra Pradesh, India. He has published a number of papers in various national \& international journals \& conferences $\&$ done a number of in-house $\&$ industry projects. He has also presented a number of guest lectures and various seminars and participated in a number of courses, seminars, workshops, symposiums in the various parts of the country in different institutions and also conducted a few courses. He is also guiding a number of Ph.D 
students. His area of interests are neural networks, fuzzy logic, power electronics, power systems, artificial intelligence, Matlab, Renewable energy sources, etc.

Dr. B. V. Sankar Ram received the B.E. degree in Electrical Engg. from Osmania University \& M.E. degree in Power Systems from Osmania University, Hyderabad, Andhra Pradesh, India. He received his Ph.D. degree in Electrical Engg. from JNTU, Hyderabad, India. He obtained Diploma in Candidate Management Finance. He has got a teaching experience of more than 20 years.
Currently, he is working as Professor in JNTU College of Engg. Hyderabad, India in the Dept. of Electrical Engg. He has published a number of papers in various national $\&$ international journals \& conferences $\&$ done a number of in-house $\&$ industry projects. He is also guiding a number of Ph.D. students (research scholars) in various topics of engg. He has specialized in power systems. His research interests include power system reliability and Flexible AC Transmission systems, power electronics \& it is applications. 